\title{
EL NECESARIO CONTROL AL GOBIERNO. UN ANÁLISIS \\ EN EL NUEVO ESCENARIO AUTONÓMICO TRAS LAS ELECCIONES DE MAYO DE 2015
}

ANDRÉS IVÁN DUEÑAS CASTRILLO 
1. INTRODUCCIÓN. 2. EL PARLAMENTO EN LAS COMUNIDADES AUTÓNOMAS ANTES Y DESPUÉS DE LAS ELECCIONES AUTONÓMICAS DE 2015. 2.1. El modelo institucional autonómico. 2.2. El cambio de paradigma en el nuevo escenario partidista. 3. LA FUNCIÓN DE CONTROL AL GOBIERNO. 3.1. La actualidad de la función de control al Gobierno. 3.2. El caso concreto de las Comunidades Autónomas. Algunas peculiaridades. 3.2.1 Peculiaridades desde el punto de vista del control al Gobierno por la oposición. 3.2.2 Peculiaridades desde el punto de vista de la participación en el Parlamento. 4. CONCLUSIONES. 


\title{
EL NECESARIO CONTROL AL GOBIERNO. UN ANÁLISIS EN EL NUEVO ESCENARIO AUTONÓMICO TRAS LAS ELECCIONES DE MAYO DE $2015^{1}$
}

\author{
ANDRÉS IVÁN DUEÑAS CASTRILLO² \\ Profesor de Derecho Constitucional \\ Universidad de Valladolid
}

\section{INTRODUCCIÓN}

La desafección ciudadana provocada por la crisis de la representación es un hecho que también ha llegado a las Comunidades Autónomas. Al mismo tiempo, los Parlamentos autonómicos han aumento su riqueza ideológica con la entrada de nuevos partidos políticos, algo que, sin duda, dificulta la gobernabilidad y los posibles acuerdos a los que se puedan llegar para solucionar este problema.

Este mayor pluralismo político ha traído como consecuencia que el Parlamento haya incrementado su actividad y se hayan reformado ya, en algunos casos, sus normas de ordenación para adaptarlas a la nueva realidad, como en las Cortes de Castilla y León, las Cortes Valencianas, las Cortes de Aragón o la Asamblea de Extremadura³;

1 El presente estudio se realiza en el marco del Proyecto de Investigación DER2016-75993-P, sobre «España ante Europa: retos nacionales en materia de derechos humanos», que se desarrolla entre el 30 de diciembre de 2016 y el 29 de diciembre 2020. Investigación cofinanciada por el Fondo Social Europeo.

${ }^{2}$ Universidad de Valladolid. Departamento de Derecho Constitucional, Procesal y Eclesiástico del Estado. Facultad de Derecho. Facultad de Derecho. Plaza de la Universidad, s/n, 47002 - Valladolid. Email:andresivan.duenas@uva.es

3 Boletín Oficial de la Asamblea de Extremadura, n. ${ }^{\circ} 28,31$ de julio de 2015. 
o se hayan registrado iniciativas en este sentido, como ha sucedido también en Castilla y León ${ }^{4}$ y Extremadura ${ }^{5}$ o Navarra ${ }^{6}$.

Los Parlamentos autonómicos, al menos hasta el nuevo escenario surgido tras las últimas elecciones autonómicas, han tenido una menor importancia que el Poder Ejecutivo en las Comunidades Autónomas. Sin embargo, a la luz de la actual situación, la institución parlamentaria parece recobrar parte del protagonismo perdido, debido, en este caso, a la finalización de mayorías absolutas y la necesidad de mayor diálogo entre los actores políticos de cara a garantizar la gobernabilidad de cada territorio. Por esto mismo, es un hecho que la función de control al Gobierno se erige, dentro del Parlamento, como una actividad de especial trascendencia. A la vez, el escenario pluripartidista ha permitido la incorporación al Parlamento de voces que demandaban mayor protagonismo de las instituciones de democracia participativa. Esto ha traído como consecuencia reformas reglamentarias que han dado más protagonismo a estos instrumentos, entendidos como formas de control al poder. A pesar de la elevada fragmentación partidista, se han logrado consensos que resulta interesante observar.

No se trata en esta comunicación de analizar cuál es la forma de gobierno de las Comunidades Autónomas, algo que iría mucho más allá de esta aportación al debate, aunque se aluda a ello de manera obligada. Lo que se pretende en estas líneas es hacer una pequeña exploración sobre el papel de los Parlamentos autonómicos en el control al Gobierno, enumerar alguna propuesta para mejorarlo e intentar responder a una serie de preguntas como las siguientes: ¿es necesario un cambio de concepción en la dialéctica del control Parlamento-Ejecutivo para pasar a una lógica de oposición-Gobierno? ¿Es posible que la introducción de nuevas formas de participación mejore el control democrático de la acción gubernamental a través del Parlamento? ¿Son las Comunidades Autónomas un buen escenario en el que se puedan probar nuevas fórmulas para luego exportarlas al ámbito estatal? ¿Ha mejorado el control en los Parlamentos autonómicos con la nueva relación de fuerzas políticas y se ha aprovechado esta situación para realizar cambios suficientes en los Reglamentos parlamentarios?

\section{EL PARLAMENTO EN LAS COMUNIDADES AUTÓNOMAS ANTES Y DESPUÉS DE LAS ELECCIONES AUTONÓMICAS DE 2015}

\subsection{El modelo institucional autonómico}

Es por todos sabido que el modelo territorial español resultante de los acuerdos políticos es el de un modelo descentralizado en Comunidades Autónomas con Poder Legislativo propio y con una forma de gobierno parlamentaria. Este modelo, sin

${ }^{4}$ Boletín Oficial de las Cortes de Castilla y León, n. ${ }^{\circ}$ 290, 19 de junio de 2017.

${ }^{5}$ Boletín Oficial de la Asamblea de Extremadura, n. ${ }^{\circ} 34,9$ de septiembre de 2015.

${ }^{6}$ http://www.parlamentodenavarra.es/es/expedientes/9-15otl-00001 
embargo, no fue el previsto por el constituyente, que sólo pensó en una organización institucional así para las Comunidades Autónomas que se constituyeran por la llamada vía rápida, como estipula el art. 152.1 CE.

Siguiendo a ARAGÓN REYES, de los artículos 147.2 c) y 148.1.1. a CE se desprende que no cabe Comunidad Autónoma sin instituciones de autogobierno, pero queda reservado al principio dispositivo la calificación, política o administrativa, determinación (número y clase) y composición y funciones de los órganos de autogobierno; aunque dicho principio dispositivo se vea limitado por normas constitucionales como el mencionado art. $152 \mathrm{CE}^{7}$.

Así, el constituyente se refirió expresamente a las llamadas Comunidades Autónomas de vía rápida para que éstas contaran con un Parlamento con funciones legislativas elegido con arreglo a un sistema de representación proporcional que designara a un Presidente, constitucionalizando, de esta manera, la forma de gobierno parlamentaria.

Es posteriormente cuando, a través de los acuerdos políticos, el resto de Comunidades optó por acogerse a este mismo modelo desde el principio, lo que supuso «una recepción acrítica de los modelos organizativos tradicionales» ${ }^{8}$. Pero no tenía por qué haber sucedido así. Por ejemplo, aunque Andalucía sea una de las Comunidades Autónomas vinculadas por el art. 152 CE, su anteproyecto de Estatuto de 1975 recogía una diferenciación entre el Presidente de la Comunidad y el Jefe de Gobierno?. Dicho de otra manera, distinguía lo que podríamos considerar el Jefe de Estado y del Ejecutivo en la Comunidad Autónoma.

Sin embargo, hoy día sigue existiendo una excesiva semejanza de los Parlamentos Autonómicos con el modelo del Congreso de los Diputados. La doctrina está de acuerdo en que «formalmente, las Comunidades Autónomas reproducen el modelo estatal» ${ }^{10}$ y que, además, existe una «tentación por la reproducción mimética al modelo estatal» ${ }^{11}$, aunque, como veremos, también se acaban de introducir diferencias entre ellos.

La STC 225/1998 ha parecido cerrar el modelo institucional autonómico y su principio dispositivo, dado que realizó una interpretación extensiva del art. 152.1 $\mathrm{CE}$, al establecerlo como canon de constitucionalidad para todas aquellas Comunidades Autónomas que hubieran decidido seguir un modelo basado en la autonomía

7 Aragón Reyes, M., Estudios de Derecho Constitucional, CEPC, 3. a ed., Madrid, 2013, pp. 847-849.

8 Pendás García, B., «Gobierno y forma de gobierno de las Comunidades Autónomas. Reflexiones sobre el dogma de la homogeneidad y sus límites», en Documentación Administrativa, n. ${ }^{\circ} 215$, julio-septiembre 1988, p. 85.

9 Aguiló Lucía, L., «Los estatutos de autonomía y el control parlamentario», en Ramírez, M. (ed.), El control parlamentario del Gobierno en las democracias pluralistas, Labor, Madrid, 1978, p. 318.

10 Tudela Aranda, J., «El Parlamento autonómico y la calidad de la democracia», en Tudela Aranda, J. (ed.), Los Parlamentos autonómicos en tiempos de crisis, Fundación Manuel Giménez Abad, Zaragoza, 2015, p. 27.

11 Durán Alba, J.F., «El cierre del sistema institucional castellano y leonés tras la última reforma estatutaria: semejanzas y diferencias con el modelo estatal», en Revista Jurídica de Castilla y León, n. ${ }^{\circ}$ extra 1, 2004, p. 178. 
política, convirtiéndolo en limitador del principio dispositivo ${ }^{12}$ (si bien es cierto que esta sentencia no fue unánime y el magistrado Cruz Villalón adujo lo contrario en su voto particular, con el que se sitúa gran parte de la doctrina ${ }^{13}$ ). No sucedió así en el modelo que sirvió como ejemplo al constituyente de 1978, el Estado integral republicano, donde hubo Comunidades Autónomas que decidieron implantar una forma de gobierno presidencialista ${ }^{14}$, pero esta es una cuestión que se escapa de este trabajo.

No se puede discutir que en cualquier fórmula de gobierno parlamentaria, como es la estatal y la autonómica, el Parlamento, como única institución que cuenta con una legitimación popular directa, es —y debería ser — el órgano central del sistema. Así, KELSEN definía al Parlamentarismo como aquel sistema en el que la formación de la voluntad del Estado se decidía «mediante un órgano colegiado elegido por el pueblo en virtud de un derecho de sufragio universal e igual» ${ }^{15}$. El uso del condicional es debido a que la doctrina española más destacada ha escrito sobre el problema que conlleva el hecho de que el Presidente del Gobierno en España tenga una situación de preeminencia sobre el Poder Legislativo ${ }^{16}$. Por eso, se ha calificado nuestra forma de gobierno como «parlamentarismo presidencial», "parlamentarismo presidencialista» ${ }^{17}$ $\mathrm{o}$ "presidencialismo con apariencia parlamentaria» ${ }^{18}$. Antes, otros prefirieron llamar a esta forma de gobierno «sistemas primerministeriales» ${ }^{19}$. Por tanto, estamos ante «una grave alteración del régimen parlamentario, pues, como consecuencia de esa transformación fáctica, nuestro Presidente disfrutaría, incluso, de más poderes que el jefe de Estado de una república presidencialista, pero con menos controles» ${ }^{20}$.

Llevándolo al terreno que se está tratando, la preeminencia del Ejecutivo se acentúa en las Comunidades Autónomas, debido a la doble condición que tiene el Presidente de éstas como representante supremo de la misma, algo reservado al Rey en el

12 Durán Alba, J.F., «Las instituciones de autogobierno y otros órganos autonómicos ante el proceso de reforma estatutaria», en La Reforma de los Estatutos de Autonomía, Junta de Castilla y LeónRevista Jurídica de Castilla y León, 2005, p. 368.

13 Para Solé Tura los Estatutos, a diferencia de los demás, tramitados por la vía del art. 151 CE no tenían «la responsabilidad total y única del procedimiento de elaboración y aprobación». SoLÉ TuRA, J., «Las Comunidades Autónomas como sistemas semipresidenciales», en El Gobierno en la Constitución Española y en los Estatutos de Autonomía, Diputación de Barcelona, 1985, p. 294.

${ }_{14}$ Sobre esta cuestión, merece leer la obra de Vilas Nogueira, X., O Estatuto galego, Edicións Do Rueiro, A Coruña, 1977.

15 Kelsen, H., Esencial y valor de la democracia, Labor, Barcelona, 1934, p. 50.

16 Aragón Reyes, M., Estudios de Derecho Constitucional, op. cit., p. 497.

17 Aragón Reyes, M., «¿Un parlamentarismo presidencialista?», en Claves de Razón Práctica, n. ${ }^{\circ} 123,2002$, p. 49.

18 Aragón Reyes, M., «Planteamiento general. Partidos políticos y democracia directa», en Biglino Campos, P. (coord.), Partidos políticos y mediaciones de la democracia directa, Centro de Estudios Políticos y Constitucionales, Madrid, 2016, p. 24.

${ }^{19}$ OHeling Ruiz, H., Nuevos criterios en las relaciones entre Parlamento y Gobierno, en RAMÍREZ, M. (ed.), op. cit., p. 123 .

20 Aragón Reyes, M., «Legislatura fallida e investidura convulsa. Análisis y consecuencias», en Revista Española de Derecho Constitucional, n. ${ }^{\circ} 109,2017$, p. 30. 
ámbito estatal, y líder del Consejo de Gobierno de cada Comunidad. Así, se subraya «el locus central que tiene esta figura en la organización institucional autonómica» ${ }^{21}$. Hasta tal punto lo anterior es tal y el Poder Ejecutivo se encuentra en una situación de clara dominación sobre el Legislativo, que algunos autores han preferido calificar a los sistemas autonómicos como semipresidenciales ${ }^{22}$.

En el momento constituyente se expresaron ideas acerca de la necesidad de una figura en las Comunidades Autónomas que quedase al margen de la política específica del Consejo de Gobierno, para evitar la acumulación de poder en una persona. Se ponía como ejemplo a evitar el caso de la Cataluña durante la II República, donde Lluis Companys reunía en su persona los cargos de President de la Generalitat, President del Consell y líder de ERC ${ }^{23}$. Actualmente, esto es lo que sucede en la inmensa mayoría de Comunidades Autónomas. Esto también se produce por la reducción del debate en torno a una personalización-inmediatización debido a la nueva comunicación de masas, algo que también se podría denominar como tele-personalización o tele-inmediatización ${ }^{24}$.

Hay otros factores que apuntan hacia esta misma dirección, como la práctica de los sistemas electorales y los sistemas de partidos autonómicos, que ha contaminado esta forma de Gobierno parlamentaria con notas presidencialistas ${ }^{25}$. Es cierto, como ya apuntaba KELSEN, que la democracia moderna descansa sobre los partidos políticos ${ }^{26}$ y que éstos, junto con el Parlamento, son necesarios para garantizar un modelo como el nuestro, que ha integrado los valores de convivencia y progreso que representan la democracia ${ }^{27}$, algo propio del Estado de Partidos ${ }^{28}$ (aunque otros autores prefieren usar el término Estado con Partidos $^{29}$ ). Pero esta partidocracia «trae como consecuencia la confusión o concentración de poderes en manos del partido mayoritario o de la coalición de partidos mayoritarios, que son el auténtico centro decisorio del poder». Esto se focaliza aún más en las Comunidades Autónomas, donde las

21 Revenga Sánchez, M., «Notas sobre el procedimiento de designación del órgano colegiado ejecutivo en las Comunidades Autónomas, en Revista Vasca de Administración Pública, n. ${ }^{\circ}$ 14, 1986, p. 90.

${ }_{22}$ Véase Solé Tura, J., «Las Comunidades Autónomas como sistemas semipresidenciales», op. cit.; o Balaguer Callejón, M.L., «Derecho de disolución e investidura automática en las Comunidades Autónomas», en Revista de las Cortes Generales, n. ${ }^{\circ}$ 18, 1989.

23 Aguiló Lucía, L., op. cit., p. 317.

24 Este comentario se hacía ya 40 años atrás: Vilas Nogueira, X., «Relaciones GobiernoParlamento y sistemas de legitimación del poder», en RAMírez, M. (ed.), op. cit., p. 119.

25 Vidal Marín, T., «La investidura de los Presidentes Autonómicos: la eliminación de la designación automática. ¿Acierto del legislador?», en Repertorio Aranzadi del Tribunal Constitucional, n. ${ }^{\circ} 15,2007$, p. 3.

${ }^{26}$ Kelsen, H., op. cit.,p. 36.

27 Tudela Aranda, J., La democracia contemporánea. Mitos, velos y (presuntas) realidades, en Revista Española de Derecho Constitucional, n. ${ }^{\circ} 111,2017$, p. 131.

28 Expresión acuñada por García-Pelayo, M. en El Estado de partidos, Alianza, Madrid, 1986.

29 Solozábal Echavarría, J.J., El principio democrático y las instituciones de participación directa replanteados, en Arnaldo Alcubilla, E. y González-Trevijano, P. (dirs.), En pro de la regeneración política en España, Aranzadi, Cizur Menor (Navarra-España), 2015, p. 293. 
mayorías absolutas en casi todas las Comunidades han sido la nota preponderante y los partidos dominantes son casi consideradas como las verdaderas instituciones de la Comunidad (se pueden poner como ejemplo Andalucía — donde ha gobernado el PSOE de forma ininterrumpida desde 1982 hasta el cambio producido tras las últimas elecciones autonómicas - o Castilla y León —aquí es el PP quien lleva gobernando desde 1987—). Así, se vuelve a las carencias de la «máquina parlamentaria» de los años 20: «domino de los partidos, su poca objetiva política personal, la falta de sentido y la banalidad de los discursos parlamentarios» ${ }^{30}$, etc.

De la misma forma, propuestas como la introducción de primarias obligatorias en las leyes electorales autonómicas (algo que es, cuanto menos, de dudosa constitucionalidad) vendría a robustecer estos rasgos presidencialistas ${ }^{31}$.

Existe un tercer motivo que es el que más interesa desde el punto de vista del análisis que se realiza en este artículo: la función de control de los Parlamentos. Sobre este tema cabe secundar a TUDELA ARANDA cuando señala que «es en relación con la función de control en la que la erosión de la autonomía parlamentaria se hace manifiesta. Y es en relación con la función de control donde se hace más manifiesta la debilidad material del Parlamento, el desequilibrio lacerante con el Ejecutivo» ${ }^{32}$. De esta manera, «los gobiernos suelen estar en disposición de controlar la agenda parlamentaria en relación con estos instrumentos (de control) a través de los grupos parlamentarios de la mayoría» ${ }^{33}$. Esto se acentúa aún más si tenemos en cuenta que el Gobierno posee el «resorte eficaz» de la Presidencia de la Cámara para controlar al Legislativo ${ }^{34}$. Asimismo, el desarrollo de los diferentes reglamentos parlamentarios y las prácticas adquiridas han comprometido en exceso la eficacia de la función de control $^{35}$, sin los consiguientes contrapoderes o frenos propios de esta situación ${ }^{36}$ (o, lo que sería más grave, con un resultante funcionamiento del sistema caracterizado por la neutralización de los que ahora existen ${ }^{37}$ ),

30 Schmiтt, C., Los fundamentos histórico-espirituales del parlamentarismo en su situación actual, Tecnos, Madrid, 2008, pp. 41-42.

31 Dueñas Castrillo, A.I., «Investidura de los Presidentes autonómicos y primarias en los partidos políticos: fortalecimiento del presidencialismo parlamentario autonómico», en Revista de Estudios Jurídicos, n. ${ }^{\circ} 17,2017$, p. 28.

32 Tudela Aranda, J., «El Parlamento autonómico y la calidad de la democracia», op. cit., p. 41.

33 Tudela Aranda, J., «La renovación de la función parlamentaria de control», en Teoría y Realidad Constitucional, n. ${ }^{\circ} 19,2007$, p. 98.

34 Sevilla AndrÉs, D., «Orígenes del control parlamentario en España (1810-1874)», en Ramírez, M., op. cit., p. 143.

35 Tudela Aranda, J., «España: Gobierno, partidos y coaliciones políticas en el Estado de las autonomías», en Lanzaro, J. (ed.), Presidencialismos y Parlamentarismo. América Latina y Europa Meridional, Centro de Estudios Políticos y Constitucionales, Madrid, 2012, p. 277.

36 Tudela Aranda, J., «El parlamento autonómico y la calidad de la democracia», en PÉrezMoneo, M. y Vintró Castells, J., Participación política: deliberación y representación en las Comunidades Autónomas, Congreso de los Diputados, 2017, p. 122.

37 Garrorena Morales, A., Escritos sobre la democracia. La democracia y la crisis de la democracia representativa, Centro de Estudios Políticos y Constitucionales, Madrid, 2014, p. 148. 
lo que genera «grandes desequilibrios en nuestro sistema» ${ }^{38}$. Dicho de otra manera, «los reglamentos parlamentarios se han caracterizado por su marcado carácter pro-gubernamental, de tal forma que su diseño (...) se orienta a definir dispositivos y procedimientos que funcionan como potentes estabilizadores del Gobierno» ${ }^{39}$. Esto no es nuevo y hace ya casi cuarenta años que la doctrina apuntaba que la actividad gubernamental se había extendido a temas propios del Parlamento, hasta tal punto que se preguntaban si ello podría suponer una nueva forma de absolutismo ${ }^{40}$; y que si los Estatutos de Autonomía no arbitraban mecanismos correctores para hacer posible la responsabilidad política, la forma de gobierno de las Comunidades Autónomas se aproximaría al presidencialismo ${ }^{41}$. Es decir, que la debilidad de nuestro parlamentarismo se debe también, principalmente, a la escasa capacidad de control político del Legislativo sobre el Ejecutivo ${ }^{42}$.

Esto es algo que también se da en otros países con unas características similares al nuestro. Así, en Italia, para evitar lo que se denominó como «complejo del tirano», se optó por fortalecer a los partidos políticos en el momento constituyente. Posteriormente, tras la reforma electoral de los años 90 y con la llegada al poder de Berlusconi, se ha dicho que en este país existe una elección casi popular del Presidente del Consejo de Ministros ${ }^{43}$, sin que su forma de gobierno sea presidencialista o semipresidencialista. Incluso, se afirma que la tendencia al modelo presidencial es universal y que el centro de gravedad de la democracia se habría trasladado de la relación entre representantes y representados a la relación entre gobernantes y gobernados ${ }^{44}$.

En resumen, se podría decir que los Parlamentos autonómicos han visto erosionada su posición institucional fruto de una deriva presidencialista de la forma de gobierno y por el debilitamiento de sus funciones ${ }^{45}$. Dicho de otra manera, que la crítica a la inutilidad del Parlamento frente al protagonismo de los Ejecutivos ${ }^{46}$ es mayor en las Comunidades Autónomas. Y esto no es algo nuevo. SCHMITT ya apuntó como una crítica a la democracia el dominio total o absolutismo de la mayoría parlamentaria ${ }^{47}$.

38 Ibidem, p. 284.

39 Paniagua, J.L., España: un parlamentarismo racionalizado de corte presidencial, en LANZARO, J. (ed.), op. cit., p. 238.

40 RiezU, J., «Control y reducción del Parlamento por el Gobierno o relaciones del Legislativo y del Ejecutivo en la realidad política», en RAmírez, M. (ed.), El control parlamentario del Gobierno en las democracias pluralistas (el proceso constitucional español), Labor, Barcelona, 1978, p. 88.

41 Martínez de la PeÑa González, D., «La responsabilidad política en la región: el control del Gobierno por la Asamblea», en Ramírez, M. (ed.), op. cit., p. 338.

42 Aragón Reyes, M., «Planteamiento general: partidos políticos y democracia directa», op. cit., p. 24 .

43 Pasquino, G., «El parlamentarismo al estilo italiano», en LANZARO, J., op. cit., p. 311.

44 Astarloa Huarte-Mendicoa, I., El parlamento moderno. Importancia, descrédito y cambio, Iustel, Madrid, 2017, p. 135.

45 Pérez-Moneo, M. y Vintró Castells, J., «Conclusiones», en Pérez-Moneo, M. y Vintró Castells, J., op. cit., p. 432.

46 Astarloa Huarte-Mendicoa, I., op. cit., p. 119.

47 Aragón Reyes, M., «Estudio preliminar», en Schmitt, C., op. cit., p. XXV. 


\subsection{El cambio de paradigma en el nuevo escenario partidista}

El nuevo escenario surgido tras las elecciones autonómicas de 2015 puede hacer que el Parlamento recobre, al menos en parte, su situación de centralidad política, debido al mayor pluralismo existente en su seno y al posible agotamiento, no se sabe si momentáneo, del bipartidismo en España, como apuntan algunos autores ${ }^{48}$. Éste ya no es tal en las Comunidades Autónomas en la presente legislatura, como se observa en las siguientes tablas:

\section{COMPOSICIÓN DE LOS PARLAMENTOS AUTONÓMICOS EN LA LEGISLATURA 2011-2015}

\begin{tabular}{|l|c|c|c|l|}
\hline & PP & PSOE & IU & \multicolumn{1}{|c|}{ OTROS } \\
\hline Andalucía & 50 & 47 & 12 & \\
\hline Aragón & 30 & 22 & 4 & 7 (PAR)/4(CHA) \\
\hline Asturias & 10 & 16 & 5 & $13(\mathrm{FAC}) / 1(\mathrm{UPyD})$ \\
\hline Canarias & 21 & 15 & & $21(\mathrm{CC}) / 3(\mathrm{NCa})$ \\
\hline Cantabria & 20 & 7 & & $12(\mathrm{PRC})$ \\
\hline Castilla y León & 53 & 29 & 1 & 1 (UPL) \\
\hline Castilla-La Mancha & 25 & 24 & & \\
\hline Cataluña & 19 & 20 & 13 & $50(\mathrm{Ciu}) / 21(\mathrm{ERC}) / 9(\mathrm{C}$ 's)/3 (CUP) \\
\hline Comunidad de Madrid & 72 & 36 & 3 & 8 (UPyD) \\
\hline Comunidad de Murcia & 33 & 11 & 1 & \\
\hline Comunidad Valenciana & 55 & 33 & 5 & 6 (Compromís) \\
\hline Extremadura & 32 & 30 & 3 & \\
\hline Galicia & 41 & 18 & $9(\mathrm{AGE})$ & 7 (BNG) \\
\hline Islas Baleares & 35 & $24^{49}$ & & \\
\hline La Rioja & 20 & 11 & & 2 (PR) \\
\hline Navarra & 4 & 9 & 3 & $19(\mathrm{UPN}) / 8(\mathrm{Na}-\mathrm{Bai}) / 7(\mathrm{Bildu})$ \\
\hline País Vasco & 10 & 16 & & 27 (PNV)/21 (Bildu)/1 (UPyD) \\
\hline
\end{tabular}

48 Veáse AzPitarte SÁnCHEZ, M., «El agotamiento del bipartidismo. Crónica política y legislativa del año 2015», en Revista Española de Derecho Constitucional, n. ${ }^{\circ}$ 106, 2016; o SÁNCHEZ MuÑoz, O., «El fin (momentáneo) del bipartidismo en España: análisis de los resultados electorales de 2015 y 2016», en Revista Española de Derecho Constitucional, n. ${ }^{\circ}$ 109, 2017.

49 PSOE, PSM-IV-ExM, PSOE-PACTE, PSM-EN, GxI+PSOE. 


\section{COMPOSICIÓN DE LOS PARLAMENTOS AUTONÓMICOS EN LA ACTUAL LEGISLATURA}

\begin{tabular}{|c|c|c|c|c|c|}
\hline & $\mathrm{PP}$ & PSOE & PODEMOS & C's & OTROS \\
\hline Andalucía $^{50}$ & 33 & 47 & 15 & 9 & $5(\mathrm{IU})$ \\
\hline Aragón & 21 & 18 & 14 & 5 & $6(\mathrm{PAR}) / 2(\mathrm{CHA}) / 1(\mathrm{IU})$ \\
\hline Asturias & 11 & 14 & 9 & 3 & $5(\mathrm{IU}) / 3(\mathrm{FAC})$ \\
\hline Canarias & 12 & 15 & 7 & & $18(\mathrm{CC}) / 5(\mathrm{NCa}) / 3(\mathrm{ASG})$ \\
\hline Cantabria & 13 & 5 & 3 & 2 & $12(\mathrm{PRC})$ \\
\hline Castilla-La Mancha & 16 & 14 & 3 & & \\
\hline Castilla y León & 42 & 25 & 10 & 5 & $1(\mathrm{IU}) / 1(\mathrm{UPL})$ \\
\hline Cataluña & 11 & 16 & 11 & 25 & 62 (JxSí)/10 (CUP) \\
\hline Comunidad de Madrid & 48 & 37 & 27 & 17 & \\
\hline Comunidad de Murcia & 22 & 13 & 6 & 4 & \\
\hline Comunidad Valenciana & 31 & 23 & 13 & 13 & 19 (Compromís) \\
\hline Extremadura & 28 & 30 & 6 & 1 & \\
\hline Galicia & 41 & 14 & 9 (EN MAREA) & & $6(\mathrm{BNG})$ \\
\hline Islas Baleares & 20 & 14 & 10 & 2 & $7(\text { otros })^{51} / 6(\mathrm{MES})$ \\
\hline La Rioja & 15 & 10 & 4 & 4 & \\
\hline Navarra & 2 & 7 & 7 & & $\begin{array}{l}15(\mathrm{UPN}) / 9(\text { Geroa-Bai)/ } \\
8(\mathrm{Bildu}) / 2(\mathrm{IU})\end{array}$ \\
\hline País Vasco & 9 & 9 & 11 & & 29 (PNV)/17 (Bildu) \\
\hline
\end{tabular}

Fuente: Ministerio del Interior.

Teniendo en cuenta los anteriores resultados, hemos pasado, antes de 2015, de tener nueve Parlamentos autonómicos con mayorías absolutas, es decir, la mayoría de Comunidades Autónomas (Galicia, Cantabria, Comunidad Valenciana, Comunidad de Murcia, Castilla-La Mancha, Comunidad de Madrid, Castilla y León, La Rioja e Islas Baleares) a tener uno sólo (Galicia) y que las demás autonomías se hayan visto obligadas a celebrar pactos de investidura para formar Gobierno (así ha sucedido en Andalucía, Aragón, Asturias, País Vasco, Cataluña, Comunidad de Murcia, Extremadura, Comunidad de Madrid, Castilla y León y La Rioja) o Gobiernos de coalición (Cantabria, Navarra, Comunidad Valenciana, Islas Baleares y Canarias). En Casti-

50 Composición previa a las elecciones de diciembre de 2018. El 3 de diciembre de 2019 los resultados electorales dieron como resultado un Parlamento con la siguiente composición: PSOE, 33; PP, 26; C's, 21, AA (Podemos+IU), 17; VOX, 12.

51 EL PI (3), MPM (3) y GxF (1). 
lla La Mancha se formó Gobierno, primariamente, gracias a un acuerdo de investidura y, después, se ha llegado a un acuerdo entre el PSOE y Podemos para que estos últimos se inserten en el Gobierno y poder aprobar, así, los presupuestos de la Comunidad Autónoma para $2017^{52}$.

El anterior acuerdo demuestra ya que el debate en el Parlamento se ha convertido en más importante, dada la obligatoriedad del visto bueno por más de un Grupo Parlamentario para aprobar los presupuestos de una Comunidad Autónoma, como ha sucedido en Castilla-La Mancha.

Aunque se ahonde en ello más adelante, otro ejemplo lo podemos ver en el caso de la crisis del gobierno murciano, donde su Presidente finalmente dimitió tras estar relacionado con casos de corrupción y después de que el Grupo Parlamentario Socialista de esa Comunidad registrara una moción de censura contra él. Lo mismo ha sucedido con el debate de la moción de censura a Cristina Cifuentes presentada por el Grupo Parlamentario de Podemos en la Asamblea de Madrid o con la constitución de hasta tres comisiones de investigación en las Cortes de Castilla y León tras más de 18 años desde que se formara la última. En definitiva, un mayor protagonismo de los Parlamentos autonómicos, no sólo desde el punto de vista del control en sentido estricto, sino también en la organización y el régimen interno del Parlamento, la investidura de los Presidentes, la aprobación de los presupuestos y la actividad legislativa, como ya han apuntado sectores de la doctrina ${ }^{53}$.

Por tanto, lo que se trata ahora es de reivindicar una profunda transformación de las instituciones protagonistas de nuestro modelo político ${ }^{54}$ y de reclamar los Parlamentos autonómicos y las Comunidades Autónomas como un buen espacio para la introducción de reformas, como organismos vivientes, que generan respuestas originales a problemas sobrevenidos ${ }^{55}$; con la idea de que la descentralización política se identifica con más y mejor democracia ${ }^{56}$.

52 https://politica.elpais.com/politica/2017/08/09/actualidad/1502304239_774273.html

53 Bilbao Ubillos, J.M., «Un nuevo ciclo político sin mayorías absolutas: los parlamentos autonómicos recobran protagonismo tras las elecciones de 2015», en Revista Jurídica de Castilla y León, n. ${ }^{\circ} 42,2017$.

54 Tudela Aranda, J., «La democracia contemporánea. Mitos, velos y (presuntas) realidades», op. cit., p. 131.

55 Porras Nadales, A., «Rendimiento institucional y eficacia parlamentaria (un estudio sobre los Parlamentos autonómicos), en Pau i Vall, F. (coord.): El Parlamento del Siglo XXI. VIII Jornadas de la Asociación Española de Letrados de Parlamentos, Tecnos, Valencia, pp. 189 y ss.

56 Biglino Campos, P., «La autonomía territorial como instrumento de democracia: participación, poderes y garantías», en Henao Correa, M. y Robledo Silva, P. (eds.), Libro de memorias. XII Congreso Iberoamericano de Derecho Constitucional, Universidad de Externado de Colombia, Bogotá, 2016, p. 819. 


\section{LA FUNCIÓN DE CONTROL AL GOBIERNO}

\subsection{La actualidad de la función de control al Gobierno}

No es el objeto de estas líneas explicar la concepción clásica de los liberales sobre el Parlamento, entendido como una reunión de representantes libres e iguales que encarnaban la soberanía de la nación, encargados de controlar a un Gobierno en el que desconfiaban. Se trata de apuntar cómo esa relación entre Parlamento-Gobierno clásica ha quedado sobrepasada merced a varios factores, como la democracia de partidos, y también que lo concebido como principal función del Parlamento, el procedimiento legislativo, ha quedado relegada y ahora es el control al Ejecutivo.

Antes incluso de que se aprobara la Constitución ya había autores que llamaban la atención sobre el posible mandato imperativo de los partidos respecto a los representantes por vía de los Grupos Parlamentarios ${ }^{57}$. La práctica posterior ha demostrado que así ha sido y que los propios constituyentes decidieron arrogar al Gobierno la centralidad de nuestro sistema, al conferir a éste en el art. 97 CE la dirección política interior y exterior, dejando al Parlamento un papel secundario ${ }^{58}$. Esto, unido a que el Gobierno está apoyado por una mayoría parlamentaria, hace que se asegure la identidad de voluntades de los Poderes Ejecutivo y Legislativos9. La consecuencia de ello es la progresiva reducción del Parlamento «a la condición de máquina de legislar dominada por el Gobierno y el traslado de la hegemonía al gabinete primero y al líder de la mayoría después» ${ }^{60}$, dejando al órgano legislativo la categoría fundamental de la función de control ${ }^{61}$.

A pesar de lo anterior, el constituyente decidió mantener en nuestra Carta Magna la concepción clásica y establecer en el art. 66.2 CE que son las Cortes Generales quienes «controlan la acción del Gobierno» (una fórmula que luego acogieron los distintos sistemas autonómicos). Sin embargo, como apuntaba RIEZU, «los sistemas políticos democráticos constitucionales han sufrido modificaciones de hecho que alteran considerablemente las formulaciones teóricas tradicionales» ${ }^{62}$, por lo que se ha de partir de la realidad práctica en el Parlamento y en las relaciones interorgánicas para hacer un buen análisis de esta situación.

57 Álvarez Conde, E., «El peligro partidocrático en el futuro funcionamiento de la Constitución Española», en RAMírez, M. (ed.), op. cit., p. 228.

58 ARANDa Álvarez, E., «Transformaciones en los instrumentos de control parlamentario», en Teoría y Realidad Constitucional, n. ${ }^{\circ} 19,2007$, p. 107.

59 SÁnchez Navarro, A.J., "Control parlamentario y minorías», en Revista de Estudios Políticos (Nueva Época), n. ${ }^{\circ} 88$, abril-junio, 1995, p. 223.

${ }^{60}$ Martínez Sospedra, M., «El régimen parlamentario y el sistema de partidos», en Ramírez, M. (ed.), op. cit., p. 206.

${ }^{61}$ Ibidem, p. 208.

${ }^{62}$ RIEZU, J., op. cit., p. 88. 
La doctrina más consolidada ya ha escrito que el conflicto político no se puede entender en términos interorgánicos ${ }^{63}$, debido a que las relaciones Legislativo-Ejecutivo descansan sobre la relación Gobierno-partido de la mayoría parlamentaria y, éstas, a su vez, en la subordinación del parlamentario individual a su jefe de grupo y al líder del partido. Es cierto que el Gobierno utiliza de manera legítima el principio de mayoría, pero éste no ha de constituir una dictadura sobre la minoría, sino que la voluntad colectiva es un resultado de las influencias recíprocas entre ambos grupos ${ }^{64}$. A mayor abundamiento, se debe tener en cuenta que el control y el Parlamento son «el hábitat natural de la oposición y las minorías, y un contrapeso imprescindible del eje mayoría-gobierno» ${ }^{65}$.

No todos los autores piensan de la misma manera y hay otros que defienden que el control se ha de seguir entendiendo de manera interorgánica: «no son ni la mayoría ni la minoría de las Cámaras quienes realizan el control, sino el Congreso o el Senado» ${ }^{66}$. Esta afirmación tiene sentido si la relacionamos con una concepción del control actualizada, y diferenciamos control en y por el Parlamento, formulada por RUBIO LLORENTE. Este autor explica que la soberanía popular sólo es compatible con la división de poderes que se frenan y contrapesan para que el poder constituido no sea ilimitado. Es preciso, a su vez, distinguir la función de control en sistemas presidencialistas y sistemas parlamentarios dado que, en los primeros, la relación entre poderes es de igualdad, ya que ambos tienen una legitimidad popular de origen. Por eso, aquí, la finalidad del control es la de someter la actuación del órgano controlado a una voluntad superior: la del pueblo. Sin embargo, en los segundos, la Asamblea ha de ser superior al Gobierno en tanto en cuanto es la única con legitimidad popular directa, por lo que la representación popular (Parlamento) ha de controlar al Ejecutivo, el cual cuenta con su confianza. En este contexto habría que tener en cuenta que la voluntad del Parlamento es la voluntad de la formalización de la voluntad de la mayoría parlamentaria formada antes del debate. Por tanto, ya no existe una dialéctica parlamentaria en la cual los diputados individuales se persuadían para tratar de convencer el uno al otro, por lo que la dualidad de sujetos Parlamento-Ejecutivo es sólo aparente. De esta forma, dado que muchos de los instrumentos de control en sentido estricto dependen del principio de mayoría, se ha de entender que el control se ejerce en toda la actividad del Parlamento, esté destinada o no al control como tal. Así, habría que distinguir entre Parlamento entendido como órgano, destinado a la formación de la voluntad popular, y Parlamento como institución, que es donde se

${ }^{63}$ Sánchez Navarro, A.J., op. cit., p. 224.

${ }^{64}$ Kelsen, H., op. cit., p. 85.

65 García Roca, J., "Control parlamentario y convergencia entre presidencialismo y parlamentarismo», en Revista Mexicana de Derecho Constitucional, n. ${ }^{\circ}$ 37, 2017.

66 Punset Blanco, R., «El control parlamentario en España: cuestiones controvertidas desde la perspectiva de la forma de gobierno», en PAU I VALL, F. (coord.), El control del gobierno en democraciaXIX Jornadas de la Asociación Española de Letrados de Parlamentos, Tecnos, Madrid, 2013, p. 162. 
debate la acción del Gobierno ${ }^{67}$. De esta manera es como también lo entiende PUNSET cuando realiza la afirmación citada ${ }^{68}$.

De otro lado, EMBID IRUJO afirma que «el control por naturaleza es responsabilidad de la mayoría parlamentaria, por cuenta en un sistema democrático y por medio de una votación, sólo la mayoría es capaz de alcanzar una propia decisión» ${ }^{69}$. Ello lo explica debido a que en el parlamentarismo racionalizado los instrumentos reglamentarios están destinados a crear mayorías parlamentarias para garantizar la estabilidad gubernamental, motivo por el cual «el control, como tal, no puede ser más que atributo último de la mayoría parlamentaria y nunca de la minoría» ${ }^{70}$.

Aunque lo anterior sea cierto, ello conlleva el riesgo de que finalmente sea la mayoría quien controle a la minoría en el propio Parlamento, lo que ya se ha convertido en un hecho para parte de la doctrina ${ }^{71}$. Algo sumamente peligroso si se concibe el control parlamentario de la acción gubernamental como una forma de frenar los excesos del Poder Público que contribuye a crear una opinión pública libre $^{72}$. El excesivo peso de los partidos políticos, concebidos como los nuevos «Príncipes» ${ }^{73}$, y su traslación a los Grupos mayoritarios, dan la sensación de que «el control es ineficaz, porque la mayoría que apoya al Gobierno no fiscaliza su actuación» ${ }^{74}$. Por eso mismo, las iniciativas de control que realiza el Grupo Parlamentario de apoyo al Gobierno, en la mayoría de casos, poco aportan a la función de control o, lo que sería peor, «ayudan a hacer oposición de la oposición» ${ }^{75}$. Lo mismo sucedería con las iniciativas de la oposición de indirizzo político que son aprobadas, algo que ya sucede como consecuencia del pluralismo de las cámaras, sobre las cuales el Gobierno hace caso omiso. A ello se le une la dificultad de exigir responsabilidad a éste, dado que la moción de censura en nuestro ordenamiento jurídico es constructiva y está destinada al blindaje del Gabinete ${ }^{76}$, aunque en el ámbito estatal, precisamente por la nueva pluralidad existente en el Congreso de

${ }^{67}$ Rubio Llorente, F., La forma del poder. Estudios sobre la Constitución, CEPC, 3.a ed., Madrid, 2012, pp. 687 y ss.

${ }_{68}$ Punset Blanco, R., «El control parlamentario en España: cuestiones controvertidas desde la perspectiva de la forma de gobierno», op. cit., p. 169.

${ }^{69}$ Embid Irujo, A., «El control parlamentario del Gobierno y el principio de la mayoría parlamentaria. Algunas reflexiones», en Revista de las Cortes Generales, n. ${ }^{\circ} 25,1992$, p. 11.

70 Ibidem, p. 17.

71 Garrorena Morales, A., Escritos sobre la democracia. La democracia y la crisis de la democracia representativa, op. cit., p. 164.

72 García RocA, J., «Control parlamentario y convergencia entre presidencialismo y parlamentarismo», op. cit., p. 12.

73 Gramsci, A., La Política y el Estado moderno, Biblioteca del Pensamiento Crítico-Diario Público, Madrid, 2009, p. 99.

74 Fernández Sarasola, I., op. cit., p. 90.

75 Aranda Álvarez, E., «Transformaciones en los instrumentos de control parlamentario», op. cit., p. 109.

76 Punset Blanco, R., «El control parlamentario en España: cuestiones controvertidas desde la perspectiva de la forma de gobierno», op. cit., p 167. 
los Diputados, se haya aprobado por primera vez desde 1978 una moción de censura. Por todo lo anterior, se puede afirmar que no existe una disponibilidad real de los instrumentos de control para las minorías, pero no sólo para poner en marcha los distintos instrumentos de control, sino también en la organización parlamen$\operatorname{taria}^{77}$, donde juegan un papel sumamente importante las Mesas. Por eso, se apunta que es necesario una adaptación a las nuevas realidades sociales de estas instituciones para consolidar las funciones que cumplen ${ }^{78}$.

Se puede entrar a valorar el importante papel que juegan los órganos de gobierno de los Parlamentos en la función de control, principalmente en la calificación y ordenación de los debates, dada su composición como reflejo del Pleno y, por tanto, controlados por la mayoría. Así, normalmente la mayoría monopoliza el orden del día y limita las posibilidades de debate y presentación de alternativas ${ }^{79}$, como ha sucedido en esta legislatura con la ilimitada presentación de prórrogas en el plazo de enmiendas a proposiciones de ley en el Congreso de los Diputados. Como analiza GÓMEZ CORONA ${ }^{80}$, el Tribunal Constitucional comenzó avalando la inadmisión de escritos por parte de la Mesa, realizando un control material que muchas veces iría más allá de las propias atribuciones que los Reglamentos reconocen al órgano $^{81}$. Sin embargo, el derecho fundamental reconocido en el art. 23.2 CE se ha convertido en la forma de acceso a la actividad parlamentaria por parte del Alto Tribunal. Además, posteriormente, el Tribunal dio un vuelco a su jurisprudencia para convertirse en garante de la correcta actuación de las Mesas, lo que supone mayores garantías para las minorías, aunque no se puede dudar de la importancia que los órganos de gobierno tienen en el Parlamento y de los posibles abusos que pueden realizar frente a las minorías.

A mayor abundamiento, el máximo intérprete de la Constitución ha señalado que «es indudable que la función de control político del Gobierno que corresponde a los parlamentarios forma parte del núcleo esencial de su condición de representantes y que, por ello mismo, las normas parlamentarias que instrumentan y ordenan el ejercicio de esa función deben aplicarse por igual a todos los miembros de la Cámara, sin que se obstaculice indebidamente su ejercicio. Por tanto, cuando ello concurra, los parlamentarios afectados pueden interponer recurso de amparo frente a los actos o resoluciones que indebidamente les impidan ejercer su mandato de representación, pues en tales

77 SÁNChez MuÑoz, O., «El afianzamiento del poder de los gobiernos autonómicos y su especial resistencia al control parlamentario», en Matía Portilla, F.J. (dir.): Pluralidad de ciudadanías, nuevos derechos y participación democrática, CEPC, Madrid, 2011, p. 318.

78 Oehling Ruiz, H., «Nuevos criterios en las relaciones entre Parlamento y Gobierno», en Ramírez, M. (ed.), op. cit., p. 130 / López Guerra, L., «Organización y funcionamiento del Parlamento de futuro», en PAu i VAll, F. (coord.): El Parlamento del siglo XXI. VIII Jornadas de la Asociación Española de Letrados de Parlamentos, Tecnos, Valencia, 2002, p. 32.

79 Astarloa Huarte-Mendicoa, I., op. cit., p. 127.

${ }^{80}$ Gómez Corona, E., «El control parlamentario en la jurisprudencia constitucional», en Teoría y Realidad Constitucional, n. ${ }^{\circ} 19,2007$, pp. 365-396.

${ }^{81}$ STC 161/1988, ATC 155/1993, STC 95/1994. 
casos la quiebra de la legalidad parlamentaria conlleva una consecuente vulneración del derecho fundamental que reconoce el art. 23.2 CE, en los términos ya expuestos» ${ }^{82}$.

Como conclusión adelantada de este primer epígrafe, es importante, a mi juicio, entender que la principal función de los Parlamentos, hoy, es la de controlar la dirección política del Gobierno. Asimismo, la fiscalización es ejercida por las minorías parlamentarias, por lo que la dialéctica Parlamento-Ejecutivo ha pasado a otra Gobierno-oposición o Gobierno-minoría ${ }^{83}$, dado que, a su vez, no sólo se controla al Gobierno, «sino también la acción de la mayoría parlamentaria que le apoya» ${ }^{84}$. Además, se ha de tener en cuenta cómo se desarrolla realmente el control parlamentario para que las normas que diseñan los procedimientos de control no sean un fracaso ${ }^{85}$, por lo que es necesario reformar dichos preceptos y entenderlos como un derecho de las minorías, como sucede en países como Alemania ${ }^{86}$. Además, ello va a suponer un fortalecimiento de los rasgos parlamentarios, un mayor equilibrio de poderes $^{87} \mathrm{y}$, principalmente, una mayor legitimación de ejercicio en las funciones del Parlamento entendido como expresión de la diversidad de voluntades.

\subsection{El caso concreto de las Comunidades Autónomas. Algunas peculiaridades}

Ya se ha analizado cómo nuestra forma de gobierno parlamentaria tiene tintes presidencialistas, algo que se enfatiza aún más en las Comunidades Autónomas ${ }^{88}$. De la misma forma, la función de control opera actualmente como el principal cometido del Parlamento, su vitalidad «depende en gran parte del lugar que se dé por la mayoría a las minorías» ${ }^{89}$ y su eficacia «de que las minorías vean reconocido ese papel» ${ }^{90}$. Lo anterior es especialmente importante porque la realización del derecho a la participación a través de representantes es tal si la mayoría y minoría parlamentaria pueden cumplir, de manera efectiva, con sus funciones ${ }^{91}$. A su vez,

${ }^{82}$ ATC $215 / 2000$, F.J. 2. ${ }^{\circ}$

83 Astarloa Huarte-Mendicoa, I., op. cit., p. 129.

${ }^{84}$ López Guerra, L., «El control parlamentario como instrumento de las minorías», en Anuario de Derecho Constitucional y Parlamentario, n. ${ }^{\circ}$ 8, 1996, p. 88.

85 Aranda Álvarez, E., «Transformaciones en los instrumentos de control parlamentario», op. cit., p. 108.

86 García Pechuán, M., «El control parlamentario del Gobierno en Alemania: el paradigma de la ley de régimen jurídico de las comisiones de investigación del Bundestag de 2001», en PAU I VALL, F., El control del Gobierno en democracia-XIX Jornadas de la Asociación Española de Letrados de Parlamentos, Tecnos, Madrid, 2013, pp. 68-70.

87 Aragón Reyes, M., Estudios de Derecho Constitucional, op. cit., pp. 706-708.

88 Tudela Aranda, J., «El Parlamento autonómico y la calidad de la democracia», op. cit., p. 25.

${ }^{89}$ García RoCA, J., «El Control del Gobierno desde la perspectiva individual del parlamentario (y a la luz del art. 23.2 de la Constitución», en Revista Vasca de Administración Pública, n. ${ }^{\circ}$ 42, 1995, p. 174.

90 Sánchez Navarro, A.J., op. cit., p. 254.

91 SÁnChez MuÑoz, O., «El afianzamiento del poder de los gobiernos autonómicos y su especial resistencia al control parlamentario», op. cit., p. 309. 
los Grupos Parlamentarios dependen de los partidos y existe una disciplina férrea en su seno, hasta tal punto que algunos autores hablan de «Parlamento grupocrático» ${ }^{92}$, por lo que casi se podría considerar que se ha resucitado el mandato imperativo dentro de estos y que se ha establecido, más bien, una relación entre elector-partido que entre elector-representante. No se puede desconocer que «las opiniones respecto de los partidos políticos han cambiado, reduciéndose el número de ciudadanos que tienen actitudes positivas, al menos en abstracto, sobre ellos: sólo el 50 por ciento dice que son instrumentos que permiten la participación ciudadana y sólo el 24 por ciento piensa que los partidos políticos se preocupan por lo que la gente piensa (solían ser el 50 por ciento hace pocos años) ${ }^{93}$. Debido a ello, se hace preciso establecer una comunicación más ágil entre elector y representante para que los partidos no supongan un obstáculo, en muchas ocasiones, para dicha comunicación $^{94}$; además de que en democracia el protagonismo principal no ha de ser de éstos en sentido estricto, sino de la sociedad ${ }^{95}$.

Teniendo en cuenta lo anterior, autores como ITURBE MACH defienden que, primero, para que un gobierno sea democrático, es necesaria la efectiva existencia de participación. A su vez, recuerda que el art. 9.2 CE obliga a los Poderes Públicos a promover la participación política, por lo que ahondar en la democracia participativa pasa por proponer nuevos procedimientos y reformas de los reglamentos parlamentarios, teniendo en cuenta las nuevas tecnologías, que estos nuevos mecanismos pueden lograr legitimar más las instituciones democráticas ante la actual situación de crisis y hacer así efectiva la participación democrática y no un mero objetivo utópico ${ }^{96}$. DÍAZ REVORIO propone, por su parte, establecer «un auténtico derecho de los electores a la comunicación con sus representantes, lo que implicaría obligaciones en esta línea para los representantes y los propios partidos ${ }^{97}$. De esta manera, habría que distinguir entre participación electoral y participación política ${ }^{98}$. CASTEL GAYÁN ha llegado a afirmar que «el modelo español se enfrenta a un nuevo reto: mejorar la calidad democrática del Estado

92 Hernández Oliver, B., «Parlamento y Estado de Partidos. La democracia contemporánea», en revista de las Cortes Generales, n. ${ }^{\circ}$ 60, 2003, p. 186.

93 OÑate Rubalcaba, P., «La representación política en España: las perspectivas de los ciudadanos y de los diputados», en Llera Ramo, F.J. (coord.), Desafección política y regeneración democrática en la España actual: diagnósticos y propuestas, CEPC, Madrid, 2016, pp. 122-123.

94 Díaz Revorio, F.J., Estado, Constitución, Democracia. Tres conceptos que hay que actualizar, Palestra Editores, Lima, 2017, p. 102.

95 Vidal Prado, C., «El derecho de participación política y la representación», en Revista Facultad de Derecho y Ciencias Políticas, n. ${ }^{\circ}$ 96, 1996, p. 103.

96 ItUrbe MACH, A., «Democracia participativa y publicidad parlamentaria», en PAU I VALL, F. (coord.), Parlamento y comunicación (nuevos retos)-XI Jornada de la Asociación Española de Letrados de Parlamentos, Tecnos, Madrid, 2005.

97 Díaz Revorio, F.J., op. cit., p. 103.

98 Font Fábregas, J. y Fontcuberta Rueda, P., «Participación política versus participación electoral» en Papers: revista de sociología, n. ${ }^{\circ} 134,1990$, pp. 45-61. 
autonómico a través de un proceso que fomente la democracia participativa en su funcionamiento» ${ }^{99}$.

Es cierto, por otro lado, que la mayoría de los problemas actuales de nuestra democracia en las Comunidades Autónomas, y también en el ámbito estatal, se deben al funcionamiento de los partidos políticos, a su falta de democracia interna y a la casi inexistencia de controles sobre los mismos. Este es un tema que ya se ha indicado en líneas precedentes, pero que es imposible abarcar en esta investigación, aunque es objeto de preocupación por la doctrina ${ }^{100}$.

Se pasa ahora a analizar, desde el punto de vista del Parlamento y del control parlamentario, cuáles son las aportaciones y los debates que se han hecho y se están dando en las diversas Asambleas autonómicas. Para ello, se parte de las siguientes premisas: primera, como sostiene la doctrina más autorizada en la materia, el reconocimiento de la autonomía política incrementa los espacios de participación y otorga mayores garantías de pluralismo que en los Estados centralizados ${ }^{101}$; segunda, las normativas autonómicas pueden servir para la «experimentación parlamentaria» ${ }^{102} \mathrm{O}$, dicho de otra manera, como «laboratorios de democracia para la reforma legislativa pendiente o en curso en otras CCAA, así como para el Estado central» ${ }^{103}$; y, por último, el control se entiende de manera amplia, en la línea mantenida por los autores ya citados, como todo acto que se produce en la Cámara, ya sea control por o control en el Parlamento.

Antes de entrar en consideraciones más concretas, es preciso señalar, de manera general, algunas de las deficiencias en el control parlamentario que afectan a las Comunidades Autónomas, a las que me he referido también al inicio del texto. Siguiendo a SÁNCHEZ MUÑOZ, esta función es más débil en los Parlamentos autonómicos debido a tres motivos principales: la falta de definición de control, la inadecuación de algunos instrumentos y la falta de repercusión en la sociedad. Los factores del desequilibrio los podríamos encontrar en la diferencia de medios entre la mayoría y la oposición de manera general y, en concreto, en materias como la presupuestaria; la actitud defensiva al control por el Ejecutivo y la evitación de someterse a éste a través, por ejemplo, de la creación de fundaciones; la falta de pluralidad en los nombramientos de órganos por parte del Parlamento; y la inadecuación de los

99 Castel Gayán, S., «Descentralización política, participación ciudadana y renovación jurídica: ¿hacia una democracia participativa?», en Revista catalana de dret públic, n. ${ }^{\circ} 43,2011$, p. 282.

${ }^{100}$ Veáse Biglino Campos, P. (coord.), Partidos políticos y mediaciones de la democracia directa, CEPC, Madrid, 2016; o Matia Portilla, F.J. (dir.), Problemas actuales sobre el control de los partidos políticos, Tirant lo Blanch, Valencia, 2016.

101 Biglino Campos. P., «Pueblo, ciudadanía y participación en el Estado autonómico», en Matia Portilla, F.J. (dir.), Pluralidad territorial, nuevos derechos y garantías, Instituto de Estudios Europeos de la Universidad de Valladolid-Comares, Granada, 2012, pp. 39 y ss.

102 SÁnChez MuÑoz, O., «El afianzamiento del poder de los gobiernos autonómicos y su especial resistencia al control parlamentario», op. cit., p 327.

103 Castellà Andreu, J.M.a ., «Democracia participativa en las instituciones representativas: apertura del Parlamento a la sociedad», en Cuadernos Manuel Giménez Abad, n. ${ }^{\circ}$ 5, junio 2013, p. 206. 
instrumentos de control clásico, ya que no están disponibles, mayoritariamente, para las minorías, pero también en relación con las programaciones de la Cámara y sus órganos de gobierno ${ }^{104}$ aunque, como se verá a continuación, hay excepciones que merecen la pena destacar y que en el actual contexto político se han podido poner en marcha.

Este menor control en las Comunidades Autónomas también se puede ver en instituciones como el decreto-ley. Tan sólo dos Comunidades previeron incorporarlo en sus Estatutos al comienzo del Estado autonómico (Cataluña y Navarra), sin que llegase a prosperar luego esta propuesta ${ }^{105}$. Sin embargo, tras la ola de reformas estatutarias de la primera década de los 2000, este instrumento normativo se ha incorporado en los Estatutos de Autonomía de las Comunidades Autónomas. Este hecho ha sido duramente criticado debido a que, entre otras razones, durante más de veinticinco años las Comunidades Autónomas han carecido de este tipo normativo y ello no ha menoscabado el funcionamiento ordinario de sus instituciones ${ }^{106}$, los Parlamentos autonómicos tienen una carga de iniciativas legislativas mucho menor que el Parlamento estatal ${ }^{107}$, todos esos Parlamentos autonómicos son unicamerales y los plazos del procedimiento legislativo son más $\operatorname{cortos}^{108}$, disponen de procedimientos especiales como las leyes de urgencia, las leyes de comisión y las leyes de lectura única que permiten acelerar la toma de decisiones legislativas ${ }^{109}$ o que en el ámbito competencial de las Comunidades Autónomas no se precisa para su eficaz ejercicio un tipo normativo de naturaleza tan urgente y excepcional ${ }^{110}$. Estos mismos argumentos los encontramos en la doctrina y en la jurisprudencia comparada para el caso de Italia. Allí se adujo que no era conveniente la incorporación de decretos-leyes en las Regiones por la ausencia de una segunda Cámara Legislativa y la mayor agilidad, por tanto, en la aprobación de las leyes regionales, por la mayor facilidad de convocatoria de la Asamblea regional que de las Cámaras estatales o por la previsión, en el ámbito regional, de procedimientos legislativos especiales para casos de urgencia o materias espe-

104 SÁNCHez MuÑoz, O., «El afianzamiento del poder de los gobiernos autonómicos y su especial resistencia al control parlamentario», op. cit., p. $310-318$.

105 Tardío Pato, J.A., «La introducción de decretos-leyes autonómicos en España», en Revista Española de Derecho Administrativo, n. ${ }^{\circ} 160,2013$, p. 320.

106 De la Iglesia Chamarro, A., «Los Decretos-leyes autonómicos en España: una aproximación crítica», en Osservatorio sulle Fonti. Revista di Diritto Costituzionale, n. ${ }^{\circ} 1,2013$, p. 2.

107 Carmona Contreras, A.M., «La incorporación de la potestad gubernamental de urgencia a los nuevos Estatutos de Autonomía: consideraciones críticas», en Revista Vasca de Administración Pública, n. ${ }^{\circ} 76,2006$, p. 20 .

108 Herráiz Serrano, O., «Teoría y práctica del Decreto-ley autonómico tras su incorporación al sistema de fuentes de algunas Comunidades», en Corts: Anuario de Derecho Parlamentario, n. ${ }^{\circ} 25,2011$, p. 107.

109 De la Iglesia Chamarro, A., «El Decreto-ley autonómico: ¿una fuente más o un nuevo problema constitucional?», en VVAA, La Constitución Política de España: estudios en homenaje a Manuel Aragón Reyes, Centro de Estudios Políticos y Constitucionales, Madrid, 2016, p. 161.

110 Aragón Reyes, M., Uso y abuso del Decreto-ley: una propuesta de reinterpretación constitucional, Iustel, Madrid, 2016, p. 115. 
cialmente complejas ${ }^{111}$. En relación con ello, se debe recordar aquí que la capacidad de poder aprobar una ley, enmendarla o convalidar un decreto-ley es también función de control al Gobierno ${ }^{112}$. Y esto es algo que se da en un nivel mucho menor para el caso de los decretos-leyes autonómicos, tanto en el plano jurisdiccional como parlamentario, debido a la diferente posición que ocupan los órganos institucionales de las Comunidades Autónomas en los procesos de control de constitucionalidad y el desarrollo de las previsiones estatutarias y de los reglamentos de los Parlamentos autonómicos ${ }^{113}$, que han reproducido la regulación estatal sin modificar sus posibles errores. Por eso hay voces que reclaman mejoras en este aspecto, como establecer como obligatorio y no como optativo para las Cámaras parlamentarias el inicio de la tramitación del decreto-ley por el procedimiento legislativo de urgencia ${ }^{114}$.

Otro de los factores aludidos que conllevan una insuficiencia en el control parlamentario es la gran importancia que tiene el Ejecutivo y, concretamente, el Presidente de la Comunidad. Para frenar este peso, sin embargo, no se han introducido excesivos cambios en los ordenamientos regionales, salvo excepciones, como se analiza posteriormente. Es interesante, de nuevo, mencionar el caso italiano. En este país, tras las reformas operadas en las regiones ordinarias por la ley constitucional n. ${ }^{\circ} 1$ de 1999 , que ha establecido la elección directa del Presidente de la Junta Regional, todos los nuevos Estatutos de Autonomía han advertido la necesidad de dotar de garantías y funciones a la oposición. Ello se concibe como una forma de introducir mecanismos de contrapesos respecto al nuevo rol del Ejecutivo y del Presidente ${ }^{115}$. De esta forma se ha avanzado en la ordenación de un estatuto de la oposición, lo que para algunos autores se concibe como «una conquista evolutiva en la historia de las formas de organización política» ${ }^{116}$.

Por otro lado, algunas Comunidades Autónomas han reducido el número de parlamentarios de sus Asambleas en la pasada legislatura, como Castilla-La Mancha, con la reforma de su Estatuto de Autonomía por la Ley 4/2014, de 21 de julio; y se presentaron iniciativas en el mismo sentido en La Rioja ${ }^{117}$ y en la Comunidad Valenciana ${ }^{118}$, aunque en estos dos casos no se llegaron a aprobar. En todos ellos los

111 Caretti, P. y Tarli Barbieri, G., Diritto Regionale, G. Giappichelli Editore, 2. ${ }^{a}$ ed, Torino, 2009, p. 126.

112 SÁnChez Agesta, L., «El régimen parlamentario en el proyecto constitucional. La relación de Gobierno y Parlamento en el proceso de decisión», en Ramírez, M. (ed.), op. cit., p. 179.

113 GonZÁlez García, I., «La trascendencia constitucional del deficiente control del decreto ley autonómico», en Revista Española de Derecho Constitucional, n. ${ }^{\circ} 111,2017$, p. 110.

114 Aragón Reyes, M., Uso y abuso del Decreto-ley: una propuesta de reinterpretación constitucional, op. cit., p. 181 .

115 BuratTi, A., Rappresentanza e responsabilità política nella forma di governo regionale, Jovene Editore, 2010, Napoles, pp. 178-188.

116 Rizzoni, G., Opposizione parlamentare e democracia deliberativa, Il Mulino, Bolonia, 2012, p. 18.

117 Boletín Oficial del Parlamento de La Rioja, serie A, n. ${ }^{\circ}$ 103, de 10 de abril de 2014.

118 Proyecto de Ley Orgánica de Reforma de los artículos 23 y 24 del Estatut d'Autonomía de la Comunitat Valenciana. Bolletí Oficial, n. ${ }^{\circ} 209$, VIII Legislatura. 
motivos esgrimidos son económicos y, en algunos casos, se confunde lo que ha de ser un Parlamento con una institución provincial, como en el caso de La Rioja. La exposición de motivos de la reforma planteada en esta Comunidad Autónoma decía lo siguiente:

«(...) La Comunidad autónoma de La Rioja de hoy es heredera de la antigua Diputación Provincial, que estaba compuesta por 24 diputados provinciales. Una corporación local con menos competencias que en la actualidad pero que en un mismo órgano, el Pleno de la Diputación, contenía el Ejecutivo y una especie de cámara de representación provincial.

Si se toma como referencia esa cifra de 24 diputados, y teniendo en cuenta esa norma de fijar una composición de número impar que facilite la formación de mayorías, podemos mantener que un Parlamento de La Rioja con 25 diputados sería una cámara legislativa autonómica ajustada a las necesidades de la sociedad riojana y más eficiente que la actual, pues desarrollaría sus funciones a un coste sensiblemente inferior».

También se suprimió el sueldo de los diputados en la Comunidad castellano manchega, recogido por algunos medios de comunicación de una manera muy preocupante - por no usar otros calificativos-, que deja mucho que desear si se pretende poner en valor la institución parlamentaria ${ }^{119}$. Esta Comunidad Autónoma se unió a La Rioja y Castilla y León, donde tampoco los diputados tienen un sueldo, sino que perciben dietas por asistencia a Plenos y Comisiones, lo que puede afectar al buen funcionamiento de la institución parlamentaria debido al abuso de convocatorias que para poco o nada sirven, provocando disfuncionalidades en su quehacer cotidiano, como muy bien han apuntado autores familiarizados con estos Parlamentos, como MATÍA PORTILLA ${ }^{120}$. De esta manera, como afirma ARANDA ÁLVAREZ, no se puede ignorar que muchos parlamentarios deberán compaginar sus ocupaciones profesionales con las tareas del escaño, por lo que este autor se pregunta si el escenario que deseamos es el de «unos parlamentarios autonómicos cansados y agobiados por el desempeño de otras labores que en unos momentos de crisis económica y confusión es más necesario que nunca el control parlamentario» ${ }^{121}$. No se tiene en cuenta que estas son condiciones para poder desempeñar la labor de representación de una forma adecuada y que es necesario un número suficiente de diputados «para que exista representatividad y los ciudadanos no tengan la sensación de que sus intereses quedan

119 El «Periodista Digital» tituló, a raíz de esta noticia, que «La Presidenta de Castilla-La Mancha pone la primera pica en los privilegios de la casta política», gracias a lo cual se escribía «un capítulo esperanzador del parlamentarismo para reconciliarlo con el pueblo»: http://www.periodistadigital.com/ castilla-la-mancha/toledo/2012/12/22/maria-dolores-garcia-page-cospedal-suprime-cortes-sueldocastilla-diputados-manchegos-mancha.shtml

120 Matia Portilla, E., «Naturaleza, composición, estructura orgánica y funcionamiento de las Cortes de Castilla y León», en Sáez Hidalgo, A. (dir.), Derecho Público de Castilla y León, Lex Nova, Valladolid, 2008, p. 270.

121 Álvarez Aranda, E., «La reducción de parlamentarios y la modificación del régimen retributivo de los miembros de las Asambleas de las Comunidades Autónomas», en Revista de Derecho Político, n. ${ }^{\circ}$ 92, enero-abril 2015, p. 150. 
sustraídos por los representantes una vez que han sido elegidos y entran a formar parte de la institución parlamentaria» ${ }^{122}$.

Fruto de este nuevo escenario político, en el Parlamento castellano y leonés se ha registrado una propuesta de reforma de su Reglamento, acompañada de una enmienda a la totalidad de texto alternativo a una proposición de ley de reforma de la Ley Electoral de esta Comunidad, que van encaminadas a lograr la profesionalización de los procuradores de Castilla y León ${ }^{123}$. Sin embargo, el panorama es desalentador porque ni siquiera se ha debatido su toma en consideración de la primera de ellas y la segunda no superó el debate de totalidad en el Pleno ${ }^{124}$.

Si se quiere poner en valor la institución parlamentaria hay que tener en cuenta que la democracia cuesta dinero y que la retribución de los parlamentarios está relacionada con la generalización del sufragio universal, la democratización de las Cámaras y es la mejor manera para evitar comportamientos corruptos ${ }^{125}$; además de que, en cuanto al número de diputados, las Leyes Electorales autonómicas se han de ver desde el punto de vista del principio de igualdad, por lo que se ha de garantizar la posibilidad de que los grupos minoritarios puedan obtener representación ${ }^{126}$, lo que mejorará, como ya se ha dicho, la función de control porque evitará el excesivo protagonismo de los Ejecutivos y su dirigismo al Grupo Parlamentario mayoritario, lo que trae como consecuencia una mayor legitimidad de ejercicio de los Parlamentos autonómicos ${ }^{127}$. En definitiva, se puede sostener que el pluralismo y respeto a las minorías, al menos hasta el momento, no ha recibido una protección suficiente en las Comunidades Autónomas ${ }^{128}$.

\subsubsection{Peculiaridades desde el punto de vista del control al Gobierno por la oposición}

Entrando en el fondo del asunto, en las siguientes líneas se analizan algunas de las particularidades en las normativas autonómicas con respecto a diversos instrumentos de control al Gobierno en manos de la oposición. A su vez, a la luz del nuevo

122 Ibidem, p. 144.

123 Artículo diez de la Propuesta de reforma del Reglamento de las Cortes de Castilla y León del Grupo Parlamentario Podemos, Boletín Oficial de las Cortes de Castilla y León, n. ${ }^{\circ} 290,19$ de junio de 2017, p. 35.781; y artículo 2 de la enmienda a la totalidad de texto alternativo presentada por el Grupo Parlamentario Podemos a la proposición de ley para la reforma de la Ley 3/1987, de 30 de marzo, Electoral de Castilla y León presentada por el Grupo Parlamentario Ciudadanos, presentada el 14 de febrero de 2017 con número de registro 1238.

124 Boletín Oficial de las Cortes de Castilla y León, n. ${ }^{\circ}$ 403, de 19 de marzo de 2018, p. 53.294.

125 Álvarez Aranda, E. «La reducción de parlamentarios y la modificación del régimen retributivo de los miembros de las Asambleas de las Comunidades Autónomas», op. cit., pp. 148-149.

126 Ibidem, p. 139.

127 Ibidem, p. 160.

128 Biglino Campos, P., «Mayorías, minorías y partidos políticos en las Comunidades Autónomas. Aires de cambio», Cuadernos de Alzate, n. ${ }^{\circ} 48-49,2016$, pp. 155 y ss. 
escenario político, es sumamente interesante observar que se demuestra la necesidad de acometer reformas para que algunas iniciativas puedan tener sentido y funcionen verdaderamente, aunque lo realmente deseable sería llevar a término, como ya se ha avanzado antes y han defendido autores como GARRORENA MORALES, la constitucionalización de un «estatuto de la oposición» ${ }^{129}$. Es recomendable que ciertos mecanismos de control queden en manos de la minoría o el derecho a incorporar puntos en el orden del día ${ }^{130}$ (esto se ha elevado a nivel constitucional en Portugal —art. 176, orden del día de la Asamblea Legislativa, art. 178 para comisiones de investigación — o Alemania — art. 44.1 Ley Fundamental de Bonn para comisiones de investigación-). Pero, por encima de estas herramientas concretas, se debería reconocer en las normas fundamentales tal estatuto de la oposición, como ya sucede en Inglaterra, ha ocurrido en muchos Länder alemanes ${ }^{131}$, se ha incorporado en la reforma constitucional francesa de $2008^{132}$; o como explicitan las Constituciones de Portugal (derecho de la oposición, art. 114) o de Colombia (estatuto de la oposición, art. 112). Es decir, se ha de reinterpretar el Parlamento como la sede privilegiada de la representación de la oposición y entender a ésta como parte constitutiva del siste$\mathrm{ma}^{133}$. Adelantando de manera general lo que se explicará a continuación, algunas Asambleas Legislativas ya han desarrollado ciertas iniciativas que se podrían vincular con este estatuto de la oposición.

Comenzando por las comparecencias, es preciso distinguir entre las que realizan las autoridades públicas y de expertos de las de grupos, asociaciones y ciudadanos, ya que tienen distintos objetivos. Los últimos «pretenden informar y asesorar a los parlamentarios —ante la opinión pública - respecto a la correspondencia entre los objetivos de la norma y la realidad social sobre la que incide» ${ }^{134}$. Esta facultad está reconocida a la minoría parlamentaria cuando lo soliciten dos Grupos Parlamentarios o la quinta parte de los miembros de la Comisión, sin que haga falta la aprobación por la Mesa o la propia Comisión, en el art. 67, apartados 3 y 4, del Reglamento de la Junta General de Asturias. De esta manera se reconoce un derecho a las minorías

129 Garrorena Morales, A., «Algunas sugerencias para renovar la función de control», en PaU I VAll, F. (coord.), Parlamento y control del Gobierno-VI Jornadas de la Asociación Española de Letrados de Parlamentos, Aranzadi, Pamplona, 1998, p. 430.

${ }^{130}$ García-Escudero Márquez, P., La regeneración del Parlamento. El papel del Congreso, el Senado y los Parlamentos autonómicos, en Arnaldo Alcubilla, E. y González-Trevijano, P. (directores), En pro de la regeneración política en España, Aranzadi, Cizur Menor (Navarra-España), 2015, p. 458.

131 Gennusa, M.E., «Lo «statuto» dell'opposizione», en Istituzioni del federalismo: revista di studi giuridici e politici, n. ${ }^{\circ} 1,2001$, pp. 241 y ss.

132 SÁnChez Navarro, A.J., «La constitucionalización de los grupos parlamentarios y la oposición en Francia», en Cuadernos de Derecho Público, n. 34-35, 2008, pp. 258 y ss. / BON. P., «La Constitución de la Quinta República cumple cincuenta años», en Revista Española de Derecho Constitucional, n. ${ }^{\circ} 85$, 2009, p. 67.

133 Petrillo, L., «Quale statuto costituzionale per l'opposizione parlamentare?», en federalismi.it, n. ${ }^{\circ}$ 3, 2005, pp. 13-20.

134 Castellá Andreu, J.M. ${ }^{a}$, op. cit., p. 208. 
que no se hace en otros reglamentos parlamentarios ${ }^{135}$. Lo mismo ha sucedido en la reforma del Reglamento de las Cortes de Aragón, cuyo art. 163 permite a diputados y Grupos Parlamentarios la propuesta de comparecencias. La Mesa de la Comisión, posteriormente, ordenará las comparecencias atendiendo a la proporción numérica de cada Grupo Parlamentario. También se regulan procedimientos específicos para las audiencias en el procedimiento legislativo en Andalucía, Islas Baleares, Cantabria, Cataluña ${ }^{136}$ o en la reciente reforma de las Cortes Valencianas.

Es interesante tratar las mociones de censura, sobre todo teniendo en cuenta que durante esta legislatura se ha tramitado una, como se decía al principio del texto, en la Comunidad de Madrid, y al menos otra fue registrada, aunque finalmente no se debatió, en la Comunidad de Murcia.

En este apartado todas las Comunidades Autónomas siguieron el modelo estatal de moción de censura constructiva, a excepción del País Vasco. No es que exista una moción no constructiva, sino que también se permite la remoción de Consejeros a través de este instrumento. Ello podría chocar con la forma de gobierno parlamentaria, ya que quien elige a su Gabinete es el Lehendakari y la propia Ley 7/1981, del Gobierno Vasco, establece que el Gobierno responde solidariamente ante el Parlamento; pero lo cierto es que su art. 49 ha permitido este tipo de censura, más bien propia de un sistema asambleario.

Resulta atractivo centrarse en lo que ha sucedido en Murcia y Madrid y las conclusiones que se puede extraer de ello. En la primera de las Comunidades Autónomas, en marzo de 2017, el PSOE registró una moción de censura para destituir al Presidente de la Comunidad ${ }^{137}$, acusado de estar implicado en varios casos de corrupción. Sin embargo, no obtuvo el respaldo de todos los partidos de la oposición dado que no había acuerdo en la forma de destituir al Presidente, aunque sí que había consenso en que éste debía abandonar su cargo. Ciudadanos, por su parte, mantenía que lo lógico era convocar elecciones anticipadas, incluso jugó con la opción de plantear una moción de censura con un candidato alternativo cuyo único cometido sería convocar, en cuanto llegara al cargo, elecciones anticipadas ${ }^{138}$. Finalmente esta moción no se debatió en sede parlamentaria porque el Presidente de la Comunidad dimitió el día anterior a su discusión ${ }^{139}$.

En el caso de la Comunidad de Madrid, fue el tercer partido en importancia en número de escaños, el Grupo Parlamentario de Podemos, quien, al igual que sucedie-

135 Larios Paterna, M.J., La participación ciudadana en la elaboración de la ley, Congreso de los Diputados, Madrid, 2003, pp. 274 y ss.

136 OsÉs Abando, J., Parlamento y sociedad civil en la función legislativa, en Quaderni Regionali, n. ${ }^{\circ} 3$, 2012, pp. 646-647.

137 https://politica.elpais.com/politica/2017/03/24/actualidad/1490349702_015101.html

138 https:/www.elconfidencial.com/espana/2017-03-28/ciudadanos-mocion-censura-psoe-murciaelecciones-pedro-antobio-sanchez_1356329/

139 https://www.elconfidencial.com/espana/2017-04-04/presidente-murcia-dimite-pedro-antoniosanchez-corrupcion_1360478/ 
ra con la primera de las mociones que se han presentado en el ámbito estatal contra Mariano Rajoy, la registró. Ello significa, en primer lugar, que la moción es un instrumento que, al menos en su iniciativa, sí que está en manos de la minoría. En este caso se presentó también debido a casos de corrupción relacionados con la «operación Lezo» ${ }^{140}$. Esta era una moción destinada al fracaso desde el mismo momento de su registro porque no contó con más apoyo que el del Grupo proponente, pero demuestra que es una forma de control en el Parlamento, aunque finalmente no se tome la decisión de destituir al Presidente ${ }^{141}$.

Sin embargo, los ejemplos anteriores demuestran claramente que la introducción del requisito de proponer un candidato alternativo a la Presidencia del Gobierno se realiza con la intención de formar mayorías negativas que están de acuerdo en derribar a un Gobierno, como sucedía en Murcia, pero no de formar uno nuevo, sin que se puedan convocar elecciones anticipadas como consecuencia de dicha moción. Aunque es sabido por todos que la introducción de este mecanismo se enmarca dentro del parlamentarismo racionalizado, no lo es menos que «la inclusión de un candidato a la presidencia comporta la unificación artificial, la confusión de dos procesos que, en la lógica parlamentaria, están claramente diferenciados, como son la exigencia de responsabilidad política mediante la moción de censura y la investidura» ${ }^{142}$. De esta forma, el Gobierno «queda salvaguardado frente al Parlamento y el equilibrio de poderes queda roto en beneficio del Ejecutivo» ${ }^{143}$. Por tanto, aunque es cierto que también se controla al Gobierno, podría caerse en la contradicción, con la actual regulación, de que «lo único que se garantiza realmente es un debate sobre el programa por el candidato propuesto por quienes han formulado la moción de censura» ${ }^{144}$. Dicho de otra manera, "podría personalizarse en exceso el debate de la moción, centrándolo no tanto en la gestión del gobierno cuestionado cuanto en la figura emergente del candidato postulado» ${ }^{145}$. En este sentido, SOLÉ TURA y APARICIO PÉREZ mantienen que, de este modo, podría darse el caso de que «el órgano presuntamente controlado, el Gobierno, se convierte en controlador y los proponentes de la moción de censura se transforman en los defensores de un programa alternativo que es objeto de examen y crítica por parte de los censurados» ${ }^{146}$ y que lo anterior puede degenerar en un debilitamiento institucional del Parlamento, mientras el Gobierno

${ }^{140} \mathrm{http} / / \mathrm{www} . e l$ periodico.com/es/politica/20170529/mocion-de-censura-podemos-cristinacifuentes-8-de-junio-6069680

141 http://www.20minutos.es/noticia/3058815/0/mocion-censura-cifuentes/

142 Soriano Hernández, E., «El uso de la moción de censura en las Comunidades Autónomas», en Asamblea: revista parlamentaria de la Asamblea de Madrid, n. ${ }^{\circ}$ 15, 2006, p. 30.

143 Medina Rubio, R.A., «La moción de censura en el anteproyecto constitucional de 1978», en RAmíreZ,, M., (ed.), op. cit., p. 282.

144 Soriano Hernández, E., op. cit., p. 34.

145 Simón YARZA, F., «La moción de censura: ¿constructiva u obstructiva?», en Revista Española de Derecho Constitucional, n. ${ }^{\circ} 103$, enero-abril 2015, p. 101.

146 Solé Tura, J. y Aparicio Pérez, M.A., Las Cortes Generales, Tecnos, Madrid, 1984, p. 210. 
se mantiene en una situación de debilidad ${ }^{147}$. Lo anterior, sin embargo, se puede poner en duda a la luz de la moción de censura triunfante presentada por el Grupo Parlamentario Socialista en el Congreso de los Diputados, cuyo uso ha sido criticado por sectores de la doctrina como un forzamiento de la institución ${ }^{148}$.

Es posible que, en casos de crisis de Gobierno, y cuando el Presidente no use su facultad de disolución del Parlamento, podría resultar interesante la fórmula de una moción de censura no constructiva donde la mayoría de Grupos esté de acuerdo en la destitución del Presidente, con el objetivo de convocar elecciones anticipadas, dado que «las elecciones representan el método democrático para designar a los representantes del pueblo, siendo lo más aproximado al control del gobierno por el pueblo que se pueda alcanzar en la moderna sociedad industrializada» ${ }^{149}$. No es, así, una mala fórmula para solucionar estas crisis. Pero la realidad es que el nuevo escenario político en dos Comunidades Autónomas donde existían mayorías absolutas antes de 2015 ha puesto de manifiesto la utilidad de la moción de censura constructiva para controlar al Gobierno y que no es del todo insatisfactoria su regulación para garantizar la estabilidad gubernamental. Asimismo, en la propuesta de reforma del Reglamento de las Cortes de Castilla y León presentada por el Grupo Parlamentario Podemos se propone una regulación similar a la del País Vasco para la remoción de Consejeros, algo que también han propuesto autores como TORRES DEL MORAL ${ }^{150}$, y una novedosa regulación para que comparezca el Presidente cuando se altere la composición de los Gobiernos de coalición en el caso de que no presentase una cuestión de confianza $^{151}$, algo que también está previsto en el art. 169 del Reglamento del Parlamento Vasco.

Por último, cabe indicar que, aunque por motivos muy distintos, relacionados con los sucesos que se están desarrollando en Cataluña, el Grupo Parlamentario de Ciudadanos en el Parlamento catalán, antes de las últimas elecciones, también anunció que podría haber presentado una moción de censura con el objetivo de convocar elecciones $^{152}$.

Continuando por las comisiones de investigación, es pacífico en la doctrina que su regulación ha de cambiar para que la iniciativa de su constitución esté en manos de la minoría parlamentaria, dado que es una de las formas más importantes de control. Por ejemplo, ARANDA ÁLVAREZ defiende que la comisión se constituya

147 Ibidem., p. 211.

148 De Carreras, F., Un Gobierno en apuros, diario El País, 26 de septiembre de 2018.

149 De Montalvo JäÄskeläIn, F., «Multipartidismo territorial y forma de gobierno parlamentaria: la West Lothian Question como paradigma de los efectos del fenómeno», en Revista Española de Derecho Constitucional, n. ${ }^{\circ} 105$, septiembre-diciembre 2015, p. 79.

$150 \mathrm{http}: / \mathrm{www}$.diariodeleon.es/noticias/castillayleon/catedratico-sugiere-introducir-mocioncensura-consejeros_1048483.html

151 Artículos 50 y 51 de la propuesta de reforma de Reglamento de las Cortes de Castilla y León presentada por el Grupo Parlamentario Podemos, Boletín Oficial de las Cortes de Castilla y León, n. ${ }^{\circ} 290,19$ de junio de 2017 , p. 35.797.

152 http://www.elmundo.es/cataluna/2017/09/06/59b051afe5fdea346b8b45f7.html 
automáticamente a instancia de una quinta parte de los parlamentarios o dos Grupos Parlamentarios si ningún otro Grupo se posicionase en contra, en cuyo caso, se debería debatir en Pleno y sólo podría ser rechazada mediante una mayoría cualificada. Teniendo en cuenta ello, para la no proliferación en exceso de este tipo de comisiones, cada Grupo debería tener limitada la propuesta de constitución para no entorpecer el trabajo parlamentario ${ }^{153}$. SÁNCHEZ MUÑOZ, por su parte, argumenta lo mismo porque, en caso de que sólo se exigiese una mayoría absoluta para que fuera rechazada, no se resolvería el problema, como había sucedido hasta 2015 en Castilla y León ${ }^{154}$.

Efectivamente, en el Reglamento de las Cortes de Castilla y León existe una interesante regulación de la constitución de las comisiones de investigación, dado que, como estipula su art. 50, se podrá constituir una comisión de investigación a instancia de dos Grupos Parlamentarios o un quinto de los procuradores, entendiéndose creada si ningún Grupo manifestare su oposición en el plazo de quince días. Si así ocurriese, se debatirá la oposición de este Grupo en el Pleno y no se creará la comisión si se opone la mayoría absoluta. Esta regulación ha impedido que se constituyese cualquier comisión de investigación durante los más 18 años de mayorías absolutas $^{155}$, pero ha posibilitado la creación de hasta tres comisiones de investigación en lo que va de legislatura ${ }^{156}$. Si la regulación fuese otra y la propuesta de constitución se debiera votar, no hubieran salido adelante, dado el empate en número de procuradores del partido que sustenta al Gobierno y el resto de la oposición. Esta previsión normativa ha mostrado, así, su virtualidad, pero se ha mostrado insuficiente, como ya se apuntaba antes. No sólo por el hecho del que advertía SÁNCHEZ MUÑOZ, sino que en la práctica la organización de los trabajos de estas comisiones no ha podido desarrollarse como es debido dado a que están controlados por la mayoría que sustenta al Gobierno, como ha criticado la oposición ${ }^{157}$. Tan es así que el Tribunal Constitucional, en la reciente sentencia 12/2019, ha declarado que se ha vulnerado el derecho a ejercer las funciones representativas (art. 23.2 CE) de los procuradores castellano y leoneses debido a que «el discurrir de los trabajos de la Comisión, desde una perspectiva estrictamente objetiva y concretamente en lo relativo a la imprescin-

153 Aranda Álvarez, E., «El Reglamento del Congreso de los Diputados: propuestas para su reforma», en Revista de Estudios Políticos, n. ${ }^{\circ} 175,2017$, p. 46.

154 SÁnCHez MuÑoz, O., «Los partidos y la desafección política: propuestas desde el campo del Derecho Constitucional», en Teoría y Realidad Constitucional, n. ${ }^{\circ}$ 35, 2015, p. 431.

155 http://www.burgosnoticias.com/actualidad/000594/las-cortes-crearan-la-segunda-comision-deinvestigacion-sobre-el-hubu-en-un-mes

156 (i) Comisión de investigación sobre los parques eólicos en Castilla y León: Boletín Oficial de las Cortes de Castilla y León, n. ${ }^{\circ}$ 30, 6 de octubre de 2015, pp. 2.560 y ss.

(ii) Comisión de investigación sobre los sobrecostes del Hospital Universitario de Burgos: Boletín Oficial de las Cortes de Castilla y León, n. ${ }^{\circ}$ 50, 10 de noviembre de 2015, pp. 5.866 y ss.

(iii) Comisión de investigación sobre la gestión de las Cajas de Ahorro: Boletín Oficial de las Cortes de Castilla y León, n. ${ }^{\circ} 291,21$ de junio de 2017, pp. 35.850 y ss.

157 http://www.elnortedecastilla.es/castillayleon/201605/10/paralizadas-comisiones-investigacioncortes-20160510100323.html 
dible práctica de las comparecencias que pueden favorecer la indagación sobre los asuntos que se investigan, se ha traducido en una dinámica que paraliza, perturba, obstruye o cuando menos dilata y demora su finalidad, y con ello restringe el ejercicio del cargo por parte de los Procuradores miembros de la misma» (FJ 5). La resolución se refiere al caso concreto de la Comisión de Investigación sobre todo el procedimiento de adjudicación e implantación de parques eólicos en Castilla y León, sobre la adquisición de terrenos en Portillo para la Construcción de un Parque Empresarial y la del edificio Centro de Soluciones Empresariales de la Junta de Castilla y León en Arroyo de la Encomienda, y sobre las oficinas del sector público de Castilla y León, con inclusión de ADE Internacional EXCAL, en ciudades del exterior de España, gestionadas directamente o a través de terceros. La constitución de comisiones de investigación así de grandes demuestra que su labor puede ser, a su vez, inabarcable.

De la anterior experiencia se demuestra que es necesaria una regulación más ambiciosa de las comisiones de investigación, en dos sentidos: uno, en su constitución $y$, otro, en la organización de sus trabajos y funcionamiento. Cabe destacar las regulaciones, entre otras, del Parlamento Europeo, que permite la constitución de comisiones de investigación a instancia de un cuarto de los parlamentarios, como estipula el art. 226 del Tratado de Funcionamiento de la Unión Europea ${ }^{158}$; pero, en especial, la regulación del Bundestag alemán.

Ya se ha señalado que en Alemania existe un derecho de la oposición a ejercer su función de control pero, en el caso de las comisiones de investigación, se va más allá, dado que se entiende que también son posibles las constituidas por la mayoría contra la minoría con el objeto de fiscalizar las actuaciones del Gobierno anterior que no pudieron ser controladas. Lo más interesante de esta regulación es que se permite crear las comisiones a instancia de un cuarto de los diputados y la regulación de sus trabajos está en manos de la minoría, ya que el Presidente estará obligado a convocar una sesión de la comisión si así se lo pide un cuarto de los miembros de ésta, entre otras consideraciones que es imposible desarrollar en este trabajo ${ }^{159}$. También el art. 141 del Reglamento de la Asamblea Nacional francesa dispone la posibilidad de que un Presidente de un Grupo de la Oposición o minoritario pueda solicitar la constitución de una comisión de investigación una vez por período de sesiones. Pero en este caso se somete a votación y se aprueba si así lo decide el Pleno por la mayoría ${ }^{160}$, por lo que la oposición no cuenta con una disposición real de este instrumento de control.

La regulación alemana, en cuanto a la constitución, es la que ha seguido el Parlamento catalán, cuyo Reglamento permite la constitución de una comisión de inves-

158 Garzón Clariana, G., «El control parlamentario del Ejecutivo en la Unión Europea», en PaU I VALl, F. (coord.), El control del gobierno en democracia-XIX Jornadas de la Asociación Española de Letrados de Parlamentos, Tecnos, Madrid, 2013, p. 25.

159 García Pechuán, M., op. cit., pp. 67 y ss.

160 García-Escudero Márquez, P., «La revitalización del Parlamento en la reforma constitucional francesa de 2008», op. cit., p. 115. 
tigación de manera automática a instancia de tres Grupos Parlamentarios o un tercio de los diputados en su art. 66.3, con la limitación de que los proponentes sólo podrán formalizar una cada año. Es interesante apuntar la propuesta de reforma de Reglamento de las Cortes de Castilla y León citada anteriormente, donde se establece, en el art. 25, que pueda ser creada por la minoría parlamentaria y que también pueda ordenar sus trabajos. A su vez, se establece la posibilidad de crear un comisionado instructor que sirva de apoyo a la comisión de investigación ${ }^{161}$.

Sobre las preguntas orales en las sesiones de control, sería deseable que éstas contaran con una mayor capacidad de improvisación y que los formulantes y miembros del Gobierno no se limitaran a leerlas y repetirlas, tanto la pregunta como la contestación, casi de forma memorística. De la misma manera, si de verdad se pretende controlar al Ejecutivo, no sería una mala propuesta que el interviniente que finalizase el turno fuese quien realiza la pregunta y no el miembro del Gobierno. Se podría tomar como referencia el Question Time británico, que permite que tras la respuesta de cada pregunta se puedan plantear cuestiones suplementarias alterándose diputados de los diferentes partidos. Se introduce, así, un elemento sorpresa que no se consigue con las preguntas ya registradas. Estas intervenciones han de estar relacionadas con la pregunta original, quedando al arbitrio del Speaker rechazarlas si se desvían de ésta ${ }^{162}$. Esta es la novedad que parece plantearse, de nuevo, en la propuesta de Reforma del Reglamento de las Cortes de Castilla y León en su art. $58^{163}$.

Sobre los instrumentos de indirizzo político, estoy de acuerdo con ARANDA ÁLVAREZ cuando manifiesta que es necesario el seguimiento de las PNL y mociones para que, cuando éstas se aprueben, no queden en «una mera recomendación que ni tan siquiera tiene un seguimiento para conocer su cumplimiento», por lo que «quizás sería necesario establecer criterios de cumplimiento y, al menos, de revisión si se han tenido en cuenta a los efectos de poder deducir la responsabilidad política» ${ }^{164}$. Aunque es cierto que los Reglamentos, en la mayoría de ocasiones, presentan disposiciones encaminadas a ello ${ }^{165}$, no lo es menos que éstas se muestran insuficientes. Así lo ha recogido la reforma del Reglamento de las Cortes de Aragón y la propuesta de reforma del Reglamento las Cortes de Castilla y León ${ }^{166}$. En especial destaca esta última, que establece la obligatoriedad de la Junta de dar cuenta del grado de cumplimiento de las PNL aprobadas en el primer mes siguiente al período de sesiones al que fue votada. Si no lo diese, el asunto se incorporará en el orden del día del siguiente Pleno

${ }_{161}$ Boletín Oficial de las Cortes de Castilla y León, n. ${ }^{\circ}$ 290, 19 de junio de 2017, p. 35.787.

162 SÁnCHEZ DE Dios, M., «El control parlamentario del Gobierno en el Reino Unido: un caso paradigmático», en PAU I VALL, F. (coord.), El control del gobierno en democracia-XIX Jornadas de la Asociación Española de Letrados de Parlamentos, Tecnos, Madrid, 2013, p. 53.

163 Boletín Oficial de las Cortes de Castilla y León, n. ${ }^{\circ}$ 290, 19 de junio de 2017, p. 35.800.

164 Aranda Álvarez, E., «La reducción de parlamentarios y la modificación del régimen retributivo de los miembros de las Asambleas de las Comunidades Autónomas», op. cit., p. 161.

165 Véase, por ejemplo, el art. 187 del Reglamento de las Cortes de Aragón o art. 154.4 del Reglamento de las Cortes de Castilla y León.

166 Artículos 274 y 60, respectivamente. 
que se celebre a instancia de cualquier Grupo Parlamentario o procurador. Es interesante mencionar que países como Francia ya han abordado, en este caso a través de la reforma constitucional de 2008, la función de evaluación de las políticas públicas de manera expresa al Parlamento ${ }^{167}$.

Sobre la debilidad de la oposición en la función presupuestaria del Parlamento y, por tanto, en el debido control de la ejecución de los presupuestos aprobados, cabe destacar la posibilidad de crear oficinas presupuestarias que sirvan de apoyo a los Grupos Parlamentarios. Esto ya se prevé en Parlamentos autonómicos como el de Andalucía (art. 62 del Reglamento), Cataluña (art. 245 del Reglamento) y Murcia (art. 81 del Reglamento); y se ha previsto en la reforma del Reglamento de las Cortes de Aragón (art. 106) y en la propuesta de reforma del Reglamento de Castilla y León (art. 31).

Para cerrar este epígrafe, es necesario hablar de los órganos de gobierno de las Cámaras. Es cierto, y no se puede dejar de tener en cuenta, que las Mesas no son, en ningún caso, los órganos de representación de los Grupos Parlamentarios, pero no lo es menos, como ya se ha apuntado, que en muchas ocasiones la mayoría ejerce su rodillo y evita que las iniciativas de la minoría puedan debatirse. Es cierto que los diputados siempre pueden acudir al Tribunal Constitucional si creen vulnerados sus derechos, pero también lo es que los pronunciamientos del Alto Tribunal muchas veces llegan tarde, por lo que no se ven reestablecidos los derechos de los parlamentarios a pesar de que se les pudiera dar la razón. También cabe el riesgo de politizar y cargar de trabajo - aún más - al Alto Tribunal cuando existen otras fórmulas que podrían solucionar este problema.

Dada la mayor pluralidad de las Asambleas autonómicas, ya se ha reformado el Reglamento de las Cortes de Castilla y León, precisamente, para favorecer esta pluralidad en su órgano de gobierno. Allí se aprobó una iniciativa presentada por todos los Grupos Parlamentarios, a excepción del Mixto, para que la Mesa pasara de cinco a seis miembros y pudieran tener representación todos los partidos con Grupo propio $^{168}$. Por su parte, en el caso de las Cortes Valencianas, a iniciativa de los Grupos Parlamentarios Socialista, Compromís y Podemos, se aprobó una reforma del Reglamento para, en este caso, avanzar en la composición paritaria de los órganos de gobierno ${ }^{169}$.

Cabe destacar la regulación contenida en el Reglamento del Parlamento de Cataluña, cuyo art. 49 dispone que las Presidencias de las Mesas de las Comisiones deberán distribuirse proporcionalmente por la Mesa de la Cámara, de conformidad con la Junta de Portavoces. Esta parece ser la línea también de la reforma del Reglamento de las Cortes de Aragón (art. 69) y de la propuesta de reforma del Reglamento de las Cortes de Castilla y León (art. 22).

167 García-Escudero MárQuez, P., «La revitalización del Parlamento en la reforma constitucional francesa de 2008», en Cuadernos de Derecho Público, n. ${ }^{\text {s }}$ 34-35, 2008, p. 99.

168 Boletín Oficial de las Cortes de Castilla y León, n. ${ }^{\circ}$ 43, 27 de octubre de 2015, p. 5.088.

169 Boletín Oficial de las Cortes Valencianas, n. ${ }^{\circ} 37,27$ de noviembre de 2015, pp. 3.428 y ss. 
Por último, sobre esta cuestión, es interesante señalar alguna otra propuesta formulada (aunque no sea estrictamente en el ámbito autonómico), como un Estatuto de neutralidad de la Presidencia de la Cámara ${ }^{170}$; o tratar de evitar que la mayoría pueda rechazar la inclusión en el orden del día de las iniciativas de la oposición ${ }^{171}$.

\subsubsection{Peculiaridades desde el punto de vista de la participación en el Parlamento}

Aunque se haya mencionado antes, es preciso recordar que muchos de los problemas de nuestro sistema democrático y, en concreto, del Parlamento, es el excesivo protagonismo de los partidos políticos y de su correa de transmisión en las Asambleas, los Grupos Parlamentarios. Éstos apenas dejan margen al parlamentario individual y algunos autores están proponiendo como medida para mejorar la legitimidad de ejercicio del Parlamento una mayor participación de la ciudadanía y solventar, así, el actual «cuestionamiento de la calidad del funcionamiento de la democracia representativa» ${ }^{172}$; de manera que los representantes hagan efectivo el derecho de participación a través de la representación configurada como un proceso desde el punto de vista democrático, para que la voluntad de los representantes sea la manifestada por los electores en el momento de la elección ${ }^{173}$.

Es cierto que en España puede que haya existido una indiferencia hacia la políti$\mathrm{Ca}^{174}$, aunque a partir del Movimiento $15 \mathrm{M}$ se produjese un repunte de la demanda de participación ciudadana. Pero lo primero puede que se deba al hecho de que no existe una percepción por parte del ciudadano de tener una influencia real a través de la participación política y porque apenas ha habido cambios en los canales convencionales en esta materia ${ }^{175}$.

Siguiendo a ALMAGRO CASTRO, no hay que olvidar que para que exista una verdadera democracia es necesaria una participación real e influyente del conjunto de

170 SÁnCHez MuÑoz, O., «Los partidos y la desafección política: propuestas desde el campo del Derecho Constitucional», op. cit., p. 432.

171 El Grupo Parlamentario Vasco propuso reformar los arts. 67.1 y 68.1 del Reglamento del Congreso para establecer que «En ningún caso podrá ser rechazada la inclusión de una iniciativa en el orden del día con la negativa de un solo grupo parlamentario aunque éste disponga de la mayoría absoluta de la cámara siempre que el resto de los grupos desee incluirlo» y que «El orden del día del Pleno puede ser alterado por acuerdo de éste, a propuesta del Presidente o a petición de dos Grupos Parlamentarios o de una quinta de los miembros de la Cámara. Para que dicho acuerdo sea considerado válido la mayoría que lo apruebe ha de estar conformada al menos por dos grupos parlamentarios». Boletín Oficial de las Cortes Generales, n. ${ }^{\circ}$ B-132-1, 6 de septiembre de 2013, pp. 1-2.

172 SÁNCHEZ MuÑoz, O., «Los partidos políticos y la desafección política: propuestas desde el campo del Derecho Constitucional», op. cit., p. 414.

173 Bastida Freijedo, F.J., «Derecho de participación a través de representantes y función constitucional de los partidos políticos», en Revista Española de Derecho Constitucional, n. ${ }^{\circ}$ 21, 1987, p. 212 .

174 GonzÁlez SAlcedo, A., «Cultura política y participación en España», en Studia Politicae, n. 24,2011, p. 7.

175 Ibidem, pp. 8-12. 
ciudadanos en la formación de la voluntad política y que el Talón de Aquiles de nuestro sistema es la falta de rendición de cuentas de los representantes, es decir, la falta de control hacia éstos. En todo caso, también hay que indicar que la participación ha de controlarse para no poner en peligro la estabilidad del sistema, pero es indudable que una mayor participación conlleva beneficios sociológicos tales como una mayor conciencia, espíritu social cooperativo o un incremento de la afección democrática hacia las instituciones que ahora se cuestionan. Esta puede ser una de las soluciones para dar respuesta a las demandas sociales provenientes de sociedades plurales y complejas como las actuales ${ }^{176}$. Dicho de otra manera, «la participación ciudadana es esencial para la democracia en tanto aporta mayor conocimiento e información de los problemas reales de las personas, así como aporta un mejor control sobre los gobernantes ${ }^{177}$. Es decir, se trata de evitar con los nuevos —o no tan nuevos- canales de participación que la supuesta independencia de los representantes no se torne en dependencia únicamente de los partidos a los que pertenecen ${ }^{178}$.

Se trata ahora, por tanto, de analizar cuáles son esos canales participativos que ya se han regulado en algunos Parlamentos autonómicos y los nuevos debates e iniciativas que se están produciendo como consecuencia del nuevo escenario partidista desde el punto de vista del control parlamentario, entendido este en un sentido amplio.

En primer lugar, cabe destacar la regulación de las preguntas de iniciativa ciudadana, reguladas en los arts. 165 del Reglamento del Parlamento andaluz, 174 del Reglamento del Parlamento canario o 178 del murciano. En todos ellos se permite a personas físicas y jurídicas la presentación de este tipo de preguntas, debiendo asumirse por los diputados para que se formulen en el Pleno. Así lo establece también el art. 17 de la reciente Ley $7 / 2015$, de 7 de agosto, de iniciativa popular de Galicia ${ }^{179}$. La misma regulación se ha insertado en el art. 266 del nuevo Reglamento de las Cortes de Aragón. Ello supone el problema, de nuevo, del protagonismo de los Grupos Parlamentarios y de que, en muchas ocasiones, este tipo de preguntas no se lleguen a formular. Por ejemplo, en el Parlamento canario, a fecha de 26 de marzo de 2019, se habían registrado tan sólo 34 preguntas de iniciativa ciudadana. Por eso, existen otras propuestas más ambiciosas que han tenido lugar en algunos Parlamentos y que han formulado, en este caso, los Grupos Parlamentarios de Podemos en la Asamblea de Extremadura y también en las Cortes de

176 Almagro Castro, D., «La participación política en la teoría democrática: de la modernidad al siglo XXI», en Revista de Estudios Políticos, n. ${ }^{\circ} 174$, p. 173 y ss.

177 Güemes, C. y ResinA, J., «Participación ciudadana y confianza. Un ejercicio de alquimia democrática», en Güemes, C., Resina, J. y Cruz-Rubio, J. (eds.), Participación ciudadana: experiencias inspiradoras en España, GIGAPP-Centro de Estudios Políticos y Constitucionales, Madrid, 2018, p. 75.

178 SAnz Moreno. J.A., «El parlamentarismo en su encrucijada: Schmitt versus Kelsen, o la reivindicación del valor de la democracia», en Revista de Estudios Políticos (nueva época), n. 162 , octubrediciembre 2013, p. 135.

179 Aunque no sea el objeto de este trabajo, no me resisto a criticar que esta regulación nunca debería haberse hecho por vía legislativa, sino a través de su incorporación en el Reglamento del Parlamento gallego, en virtud de su autonomía parlamentaria. 
Castilla y León. En el primer caso, en el art. 56, se prevé la modificación del art. 273 del Reglamento para que se incluyan en el orden del día, sin necesidad de ser asumidas por ningún Grupo Parlamentario o diputado, las cuatro preguntas de iniciativa ciudadana más votadas en la web de la Asamblea extremeña, pudiéndose plantear directamente por el proponente a través del llamado escaño ciudadano, previsto en el art. $276^{180}$. Esta propuesta de reforma del Reglamento fue rechazada ${ }^{181}$. La misma línea sigue la propuesta formulada para las Cortes de Castilla y León aunque, como se ha dicho, ni siquiera se ha llegado a discutir su toma en consideración $^{182}$.

Sobre la posibilidad de plantear PNL de carácter ciudadano, destaca la regulación gallega contenida en la referida Ley 7/2015. En su art. 16 dispone esta posibilidad, con la firma, al menos, de 2.500 ciudadanos y la necesidad de que la asuma cualquier Grupo Parlamentario para que se pueda sustanciar en sede parlamentaria. Esta regulación es la misma que en el art. 270 del nuevo Reglamento de las Cortes de Aragón, pero en este caso no se exige un número mínimo de firmas; mientras que en la propuesta de reforma del Reglamento de las Cortes de Castilla y León, en su art. 61, se establece un número mínimo de firmas del $0,1 \%$, sin la obligatoriedad de que sea asumida por ningún Grupo Parlamentario para su debate y la posibilidad de que un ciudadano actúe en representación de los firmantes en el debate parlamentario. Es una regulación muy similar a la que se proponía para el Reglamento de la Asamblea de Extremadura en el art. 275.

En cuanto al procedimiento legislativo, entendido aquí como una forma de control en el Parlamento, existen varios casos de regulaciones autonómicas que permiten que uno de los miembros de la Comisión Promotora pueda defender una ILP en sede parlamentaria. Así lo establece el art. 12 de la Ley 7/2015 gallega, que permite intervenir a la Comisión Promotora en el debate de su toma en consideración. Más recientemente, la Ley 3/2016, de 30 de noviembre, del Estatuto de los Altos Cargos de la Administración de Castilla y León reformó, en virtud de su disposición final tercera, el art. 21 de la Ley 4/2001, de 4 de julio, reguladora de la iniciativa legislativa popular y de los Ayuntamientos de Castilla y León ${ }^{183}$, para que la Comisión Promotora intervenga, en todo caso, en la Comisión correspondiente en función de la materia antes del debate de toma en consideración, pero deja abierta una posible regulación más concreta en el Reglamento de las Cortes. De esta manera, el art. 39 de la propuesta ya mencionada de reforma del Reglamento de las Cortes de Castilla y León dispone que la Comisión Promotora intervenga

180 Boletín Oficial de la Asamblea de Extremadura, n. ${ }^{\circ} 34,9$ de septiembre de 2015, pp. 15-16.

181 Diario de Sesione de la Asamblea de Extremadura, n. ${ }^{\circ} 28-\mathrm{C}, 25$ de septiembre de 2015.

182 Artículos 35 y 59 de la propuesta de reforma del Reglamento de las Cortes de Castilla y León formulada por el Grupo Parlamentario Podemos. Boletín Oficial de las Cortes de Castilla y León, n..$^{\circ}$ 290, 19 de junio de 2017, p. 35.792 y p. 35.800.

183 Se debe criticar aquí, de nuevo, la mala técnica legislativa donde en una ley que trata un tema totalmente distinto a la iniciativa legislativa popular se modifica su regulación. 
en el propio debate de toma en consideración y, en caso de que el Pleno la haga suya, la posibilidad de que lo haga en el debate de enmiendas ${ }^{184}$. También se establece que pueda retirar la ILP si entendiese que el texto final no se adecúa con el inicialmente presentado. Esta posibilidad de retirada es discutible dado que podría romper la relación representativa de los diputados, pero también se ha argumentado que «quien tiene la capacidad de iniciar, tiene la capacidad de retirar» ${ }^{185}$. La Comisión Promotora puede participar también en la fase de Comisión (aunque de manera facultativa, siempre que lo proponga algún Grupo Parlamentario) en Cataluña, incluso tiene capacidad para proponer comparecientes, lo que supone poder salvar una eventual distorsión de los contenidos propuestos por los firmantes ${ }^{186}$. Esta audiencia de los representantes de los firmantes de una ILP también está prevista en Regiones italianas como Calabria, Piamonte, Toscana o Véneto ${ }^{187}$. Las nuevas regulaciones, desde luego, y estas propuestas más ambiciosas, son formas de participación que se deben explorar para evitar la dificultad de su ejercicio y garantizar que esta institución funcione como un mecanismo real de participación ${ }^{188}$.

Dentro del procedimiento legislativo también se pueden mencionar otras formas de participación que van más allá de la propia presentación de una ILP, encaminadas a avanzar en una mayor participación ciudadana en este proceso ${ }^{189}$. Así, PRESNO LINERA reivindica una mayor participación ciudadana en las distintas fases del procedimiento legislativo como forma de concreción de la democracia deliberativa ${ }^{190}$. Con la misma finalidad, CASTELLÀ ANDREU defiende la posibilidad de introducir en los reglamentos parlamentarios la posibilidad de presentar enmiendas de iniciativa ciudadana ${ }^{191}$.

La Ley 7/2015 gallega ya introduce en su art. 15 la posibilidad de intervención popular en la elaboración de las leyes a través de la remisión de sugerencias y aportaciones a la Mesa del Parlamento de Galicia de la firma del informe de la ponencia de la iniciativa legislativa. También en las Cortes Valencianas existe la posibilidad de presentar enmiendas de carácter ciudadano. En la reforma de noviembre de 2015 se

${ }^{184}$ La propuesta no diferencia entre el debate de enmiendas en ponencia o en comisión, pero cabe interpretar que la comisión promotora sólo pueda intervenir, siempre con voz pero, como es lógico, sin voto, en los debates en comisión, dado el carácter secreto de las ponencias.

185 Aragón Reyes, M., «La iniciativa legislativa», en Revista Española de Derecho Constitucional, n. ${ }^{\circ} 16,1986$, p. 289.

186 García Majado, P., «La participación ciudadana en Cataluña a través de la iniciativa legislativa popular», en PÉrez-Moneo, M. y Vintró Castells, J., op. cit., p. 238.

187 Vizoli, N., «La democracia participativa en la legislación regional italiana», en Revista catalana de dret públic, n. ${ }^{\circ}$ 48, 2014, p. 194

188 Castel Gayán, S., op. cit., p. 303.

189 Burguera Ameve, L., «Centralidad parlamentaria e iniciativa ciudadana en el proceso legislativo», en Revista de Estudios Políticos, n. ${ }^{\circ} 171,2016$, p. 118.

190 Presno Linera, M., «La participación ciudadana en el procedimiento legislativo como parte de la esencia y valor de la democracia», en Asamblea: Revista Parlamentaria de la Asamblea de Madrid, n. ${ }^{\circ} 27,2012$, p. 86.

191 Castellà Andreu, J.M. ${ }^{\text {a }}$ op, cit., p. 212. 
incorporó en el art. 113 bis este tipo de enmiendas, que deben ser asumidas por algún Grupo Parlamentario para su debate. Una experiencia que se asemeja es la del Parlamento canario, que permite que la ciudadanía haga propuestas en las iniciativas legislativas que se presenten a través de su portal de participación ${ }^{192}$, de forma parecida a la regulación gallega (aunque en el caso canario no está como tal establecido en ninguna norma). La reciente reforma del Reglamento de las Cortes de Aragón y la propuesta en las Cortes de Castilla y León de las que se viene hablando están en la línea de lo defendido por CASTELLÀ. En el primer caso, el art. 165 regula las propuestas de enmienda de iniciativa ciudadana, pudiendo presentarse por cualquier persona física o representante de persona jurídica en los diez primeros días del plazo de presentación de enmiendas. Para que éstas puedan ser debatidas, deben ser asumidas por un Grupo Parlamentario. No se permite que lo sean por un diputado individual, algo contradictorio ya que en el art. 164 del Reglamento sí que se permite la presentación de enmiendas por parlamentarios singulares, al igual que sucede en la regulación valenciana. La propuesta castellano y leonesa es mucho más ambiciosa. En su art. 34 establece la posibilidad de presentar enmiendas a colectivos interesados por la correspondiente iniciativa legislativa que estén registrados en las Cortes de Castilla y León y a cualquier persona interesada que reúna, al menos, el 0,75\% de las firmas del censo en el plazo de un mes, pudiendo intervenir para su defensa, además, según los arts. 35 y 36, tanto en Pleno como en Comisión, a través del escaño ciudadano. Por su parte, el Reglamento del Parlamento de Andalucía, con la reforma de 2014, permite la presentación de enmiendas a los ciudadanos andaluces, a través de asociaciones representativas de sus intereses debidamente inscritas en el Registro de Asociaciones de la Junta de Andalucía. Aquí lo que se hace es institucionalizar una práctica habitual en las Cámaras: la presentación de aportaciones en forma de enmienda que hacen este tipo de entidades a los Grupos Parlamentarios y que luego registran como suyas.

Por último, se pueden mencionar interesantes regulaciones, como la establecida en el Reglamento del Parlamento de Cataluña (artículos 216 a 220), sobre el establecimiento de un Registro de Grupos de Intereses, para que puedan participar en las actividades parlamentarias, regulación que también está prevista en la propuesta de reforma del Reglamento de las Cortes de Castilla y León (art. 68).

Por tanto, se puede decir que «hoy es posible abrir ventanas para que los representados puedan, aunque tan solo sea limitadamente, participar en los ámbitos de debate y discusión parlamentaria» ${ }^{193}$.

192 http://www.parcan.es/participacion/index.py

193 Aranda Álvarez, E., «Parlamento abierto: una visión desde los principios de funcionamiento de las cámaras parlamentarias», en Revista Española de Derecho Constitucional, n. ${ }^{\circ} 111,2017$, p. 25. 


\section{CONCLUSIONES}

1. De todo el texto se puede desprender que, gracias al nuevo escenario político, parece que el Parlamento está recobrando parte de su protagonismo. Aun así, el excesivo poder del Ejecutivo en el sistema institucional autonómico y, en particular, el peso de los Presidentes, hacen ver que la función de control en las Comunidades Autónomas es más importante que en el ámbito estatal.

2. Es necesaria una nueva concepción del Parlamento que reconozca, por un lado, esa vital importancia de la función de control y avanzar de una concepción de un Ejecutivo controlado por el Legislativo a una dialéctica mayoría-oposición. De la misma forma, se ha de entender este control en sentido amplio, distinguiendo entre control por y en el Parlamento. Una propuesta ambiciosa sería la de incluir en los Estatutos de Autonomía un estatuto de la oposición reconocido como tal. En tanto en cuanto lo anterior no es posible, precisamente, por las dificultades de llegar a acuerdos en un escenario más fragmentado que antes de 2015, ya se han acometido reformas de los reglamentos parlamentarios y se han registrado otras que pueden servir como experimentación de nuevas concepciones en la función de control. Ello se puede aprovechar como ejemplo de futuras modificaciones en otras Comunidades Autónomas y en el modelo estatal. En todo caso, en las precedentes líneas se ha puesto de relieve cómo el actual escenario ha demostrado la inadecuación de algunos procedimientos parlamentarios e instrumentos, propiamente dichos, de control. La nueva situación de pluralidad en los Parlamentos puede ser un buen momento para acometer las reformas necesarias que los pongan en manos de la minoría y, también, para lograr una mayor pluralidad en los órganos de gobierno y evitar que la mayoría pueda bloquear iniciativas de la minoría.

3. Desde luego, estas nuevas discusiones no se pueden entender sin tener en cuenta el contexto de cambio de estructura partidista de las Comunidades Autónomas. La entrada en escena de nuevos actores políticos ha producido que, al menos, se discutan propuestas que antes no se habían tenido en cuenta y se ponga de relieve una novedosa forma de relación del Parlamento con la sociedad. Pero no solamente se han debatido, sino que, en algún caso, también se han aprobado modificaciones importantes en los Reglamentos parlamentarios que pueden suponer una mejora del control al Ejecutivo. Se demuestra, así, que «el laboratorio del parlamentarismo autonómico va por delante del nacional» ${ }^{194}$. En cualquier caso, sería deseable que se transformase el actual Parlamento grupocrático para evitar el excesivo peso de los

${ }^{194}$ Morales Arroyo, J.M., «Una reforma conectada con el derecho de participación política», en Ruiz-Rico Ruiz, G., Porras Nadales, A. y Revenga Sánchez, M. (coords.), Regeneración democrática y reforma constitucional, Tirant lo Blanch, Valencia, 2017, P. 211. 
partidos políticos. Una de las formas de solventar la crisis de legitimidad de ejercicio del Parlamento podrían ser las nuevas fórmulas de participación, ya existentes en algunas Comunidades Autónomas, aunque también es cierto que aún es demasiado pronto para apresurarse a hacer una afirmación categórica en este sentido. También podría serlo otorgar más peso al diputado individual.

4. Por último, como conclusión general, es imprescindible poner de nuevo el Parlamento en el centro del sistema político y enfatizar las formas parlamentarias de nuestro régimen. Reformas como la reducción y desprofesionalización de parlamentarios en Castilla-La Mancha no hacen sino empeorar la calidad de la democracia. Es necesaria una representación plural para mejorar la calidad de la relación entre representantes y representados, así como una verdadera garantía de independencia de los diputados autonómicos, que no se logra si no se profesionaliza su función. El actual momento político, es verdad, es mucho más plural que antes, lo que puede generar más dificultades para llegar a acuerdos. Pero también es cierto que se ha logrado que los Gobiernos deban rendir cuentas de su gestión con más asiduidad y, así, lograr alcanzar acuerdos con la oposición. De otro lado, como en el caso de las Cortes de Aragón, se ha demostrado que a pesar del nuevo escenario se puede llegar a consensos para mejorar la institución parlamentaria y ponerla en contexto de la actual situación social y política. En todo caso, habrá que estar atentos y observar si estas nuevas experiencias son exitosas o si, por el contrario, son insuficientes para mejorar la función de control al Gobierno y perfeccionar los frenos y contrapesos ineludibles en cualquier democracia.

Title:

The necessary control to the Goverment. An analysis in the new autonomic scenary after elections of May 2015

\section{Summary:}

1. INTRODUCTION. 2. THE PARLIAMENT IN THE AUTONOMOUS COMMUNITIES BEFORE AND AFTER THE REGIONAL ELECTIONS OF 2015. 2.1. The autonomic institutional model. 2.2. The paradigm shift in the new partisan sceanario. 3. THE CONTROL FUNCTION TO GOVERNMENT. 3.1. Currently in control function to Government. 3.2 The specific case of the Autonomous Communities. Characteristics. 3.2.1. Characteristics from the point of view of control to 
the Government by the opposition. 3.2.2. Characteristics from the point of view of participation in Parliament. 4.- Conclusions.

\title{
Resumen:
}

Este artículo analiza las consecuencias que ha traído el mayor pluralismo parlamentario tras las elecciones autonómicas de 2015. Ello ha propiciado mayores debates sobre la posición del Parlamento en el modelo institucional autonómico y reformas para mejorar la función de control al Gobierno. Lo anterior puede volver a poner en el centro del sistema institucional a la Asamblea legislativa autonómica, lo que ayudaría a rebajar los rasgos presidencialistas del modelo autonómico.

\begin{abstract}
:
This article analyzes the consequences that the more parlamentary pluralism has brought after autonomic elections of 2015. It has propitiated more debates about Parlament position in the institutional autonomic model and reforms to improve the control function to the Government. The above can put in the centre of the institucional system the autonomic Parlament, which would help to reduce the presidentialist features of the autonomic model.
\end{abstract}

\section{Palabras clave:}

Democracia, participación, Comunidades Autónomas, descentralización, federalismo, regionalismo, control, oposición.

Key words.

Democracy, participation, Autonomic Comunities, decentralization, federalism, regionalism, control, opposition. 